\title{
CHILDREN, FOOD AND POVERTY Food insecurity among primary school students in the Wellington region
}

by

Sarah Gerritsen

A thesis submitted in partial fulfilment of the requirements for the degree of M.A. (Applied) in Social Science Research

Victoria University of Wellington

2005 


\section{Abstract}

This research utilises a questionnaire, completed by 115 primary school principals in the Wellington region, to explore the link between poverty and food insecurity among children. Principals recorded the number of children estimated to be regularly hungry at school for the month of May 2004, and the number of children who regularly came to school without having eaten breakfast and who regularly had no lunch during that month. Principals also provided information on how their school responds to hungry children and gave their opinions on whether schools were responsible for solving food insecurity issues among children. Principals' responses were analysed within a critical realist sociological perspective.

This research confirms that a small but significant number of primary school children in the Wellington region experience serious food insecurity, and that food insecurity is strongly correlated with poverty. Two-thirds of children estimated to be regularly hungry are from schools in low socio-economic areas (Decile 1 to 4 schools), and nearly three quarters of children that regularly do not have lunch come from these schools. Ten percent of children in Decile 1 and 2 schools were estimated by their principal to be regularly hungry throughout the school day during May 2004.

The responses of schools to hungry children were in most instances inadequate and often ad-hoc, showing little consideration of the outcomes for children. However, the small number of schools in the Wellington region who have developed detailed policy and procedures to respond to hungry children appear to be successful in limiting stigmatisation of children and their families. This thesis argues that responses to food insecure children must consider the causes of food insecurity, and in order to prevent stigmatisation, should be founded on the principle of social justice rather than charity. 


\section{Acknowledgements}

Firstly, thank you to the principals of primary schools throughout the Wellington region that have contributed to this project. Without your support this research would not have been possible. I know you are all extremely busy people - with piles of paperwork - and I am grateful for the time and effort you gave to help me. A special thank you to the principals who spoke with me on the phone and shared their experiences and opinions on this issue. I hope these results will be of interest to you all.

My supervisor, Dr. Sandra Grey, has been more than any student could ask for in a supervisor: encouraging, understanding, challenging, intelligent, always available, and a real pleasure to talk with. Thank you so much Sandra for taking me on and demanding the best from me.

I have also greatly appreciated the guidance and friendship of the Director of the MA (Applied) Social Science Research programme, Dr. Jenny Neale. Thanks Jenny for your astuteness, timely advice and wonderful humour.

Thank you to my fellow MA (Applied) Social Science Research students and the many other friends and colleagues who have offered encouragement and advice along the way.

A big thank you to my best friend and greatest critic, Josh Dahlberg, for editing the final draft and for putting up with this obsession of mine over the past two years.

Lastly, thank you to my wonderful partner for always providing me with a sanctuary away from work. I am really grateful for your love and support. 


\section{Table of Contents}

Acknowledgements

BACKGROUND / LITERATURE REVIEW ....................................................... 10

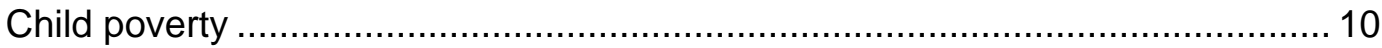

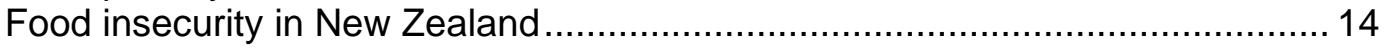

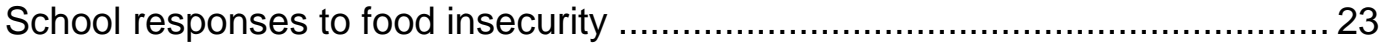

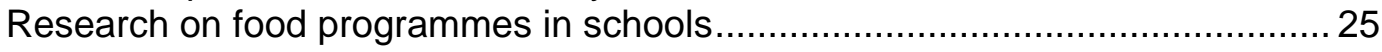

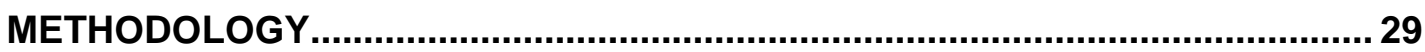

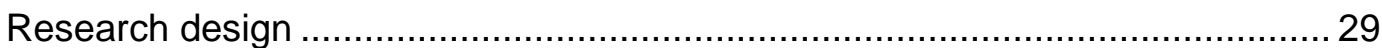

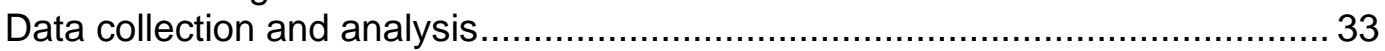

An analysis of the questionnaire ............................................................. 40

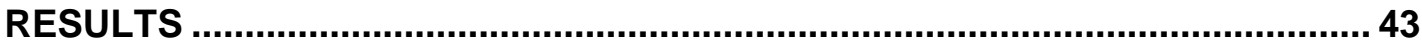

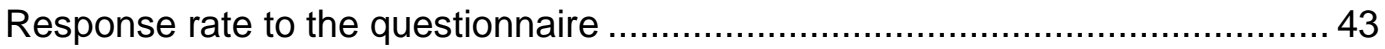

Food insecurity among children in the Wellington region................................. 43

School responses to food insecure children .............................................. 45

Principals' opinions on food insecurity among children.................................. 52

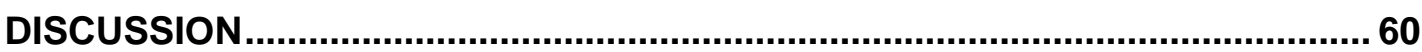

Food insecurity among children in the Wellington region.................................6 60

The provision of free food to hungry children................................................... 64

School policy and procedures for responding to food insecure children ............. 65

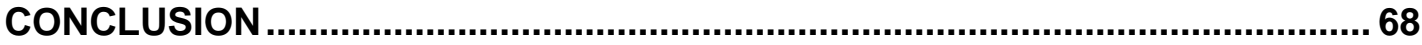

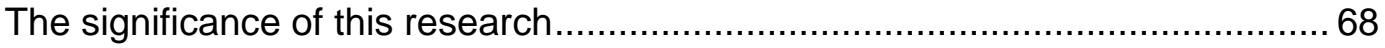

Limitations of this thesis and areas for further research ..................................69 69

Possible strategies and policy implications ................................................ 70

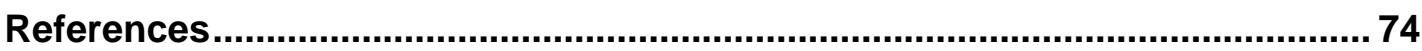

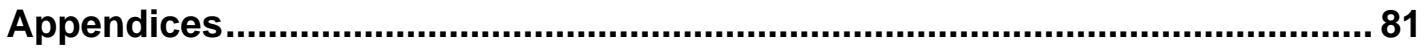

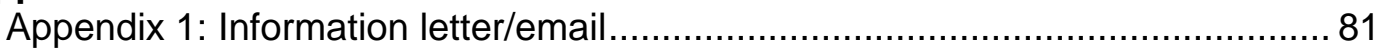

Appendix 2: Cover letter for questionnaire ................................................. 82

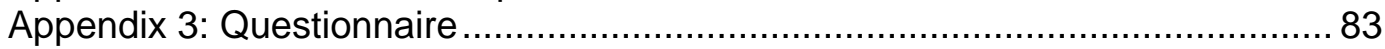

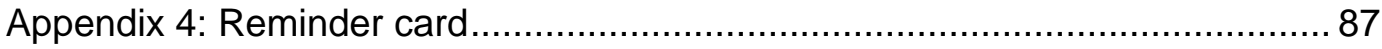

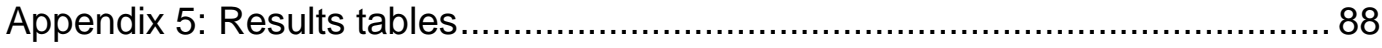

Appendix 6: Extra information provided by participating schools .................... 100 


\section{List of Figures}

Figure 1: The eight-step household food insecurity continuum............................ 3

Figure 2: School children's food insecurity continuum ........................................ 4

Figure 3: Weekly expenditure on food by income group of household .................. 16

Figure 4: A diagrammatic representation of the research design ......................... 31

Figure 5: Map of the Wellington region showing district areas used by the Ministry

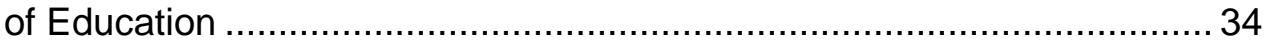

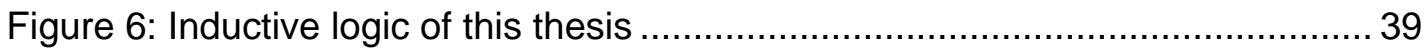

Figure 7: Bar graph showing percentage of students in each decile range estimated to experience food insecurity in May 2004. .... 44

Figure 8: Pie chart showing the source of funding for free food in schools............ 50

Figure 9: Bar graph of the opinions of Principals on the link between food insecurity and absenteeism from school by decile rating 


\section{List of Tables}

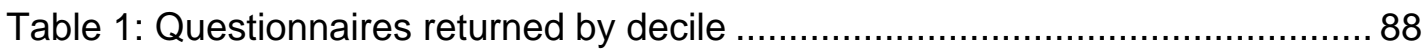

Table 2: Questionnaires returned by regional area........................................... 88

Table 3: Children estimated to be 'regularly hungry' in May 2004 by decile ........... 88

Table 4: Children estimated to regularly have no breakfast in May 2004 by

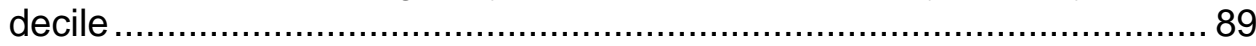

Table 5: Children estimated to regularly have no lunch in May 2004 by decile ...... 89

Table 6: Written policy in schools regarding children and food ............................. 89

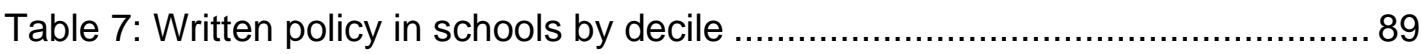

Table 8: Informal procedures in schools for teachers to follow when a child has not eaten breakfast or has no lunch ................................................ 90

Table 9: Informal procedures in schools by decile ............................................. 90

Table 10: Food provided to children who are hungry ............................................ 90

Table 11: The provision of free food to hungry children................................... 91

Table 12: The provision of free food to hungry children by decile........................ 91

Table 13: Schools that do not provide free food to hungry children by decile........ 91

Table 14: Numbers of children receiving free food by decile .............................. 92

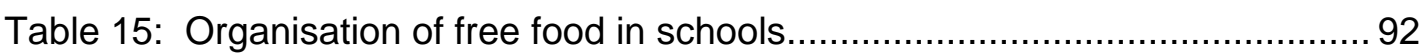

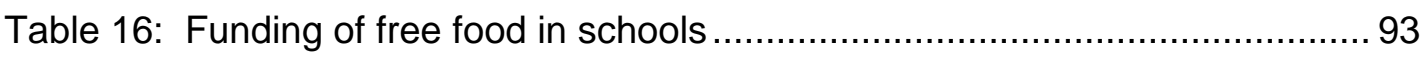

Table 17: Numbers of children referred to a Public Health Nurse in the past year due to a concern for their food security ..................................... 93

Table 18: Referrals to a Public Health Nurse by decile...................................... 94

Table 19: Numbers of children referred to Social Worker in the past year due to a concern for their food security ..................................................... 94

Table 20: Referrals to a Social Worker by decile ................................................ 94

Table 21: Correlation between numbers of hungry children in May 2004 with referrals made to a welfare professional in past twelve months............. 95

Table 22: Principals' opinions on the difficulty for parents to provide breakfast for their child(ren) every day.

Table 23: Principals' opinions on the difficulty for parents to provide breakfast for their child(ren) every day by decile

Table 24: Principals' opinions on the difficulty for parents to provide lunch for their child(ren) every day.

Table 25: Principals' opinions on the difficulty for parents to provide lunch for their child(ren) every day by decile. 
Table 26: Principals' opinions on whether parents are responsible for ensuring that their child(ren) has lunch every day

Table 27: Principals' opinions on whether parents are responsible for ensuring that their child(ren) has lunch every day by decile

Table 28: Principals' opinions on whether schools are responsible for ensuring that every child has lunch every day

Table 29 Principals' opinions on whether schools are responsible for ensuring that every child has lunch every day by decile

Table 30: Principals' opinions on whether absenteeism is sometimes the result of children having no provision for lunch

Table 31: Principals' opinions on whether absenteeism is sometimes the result of children having no provision for lunch by decile

Table 32: Principals' opinions on whether schools are an important link in the provision of social services for children

Table 33: Principals' opinions on whether schools are an important link in the provision of social services for children by decile. 


\section{INTRODUCTION}

Children's nutrition and well being are the foundation of a healthy, productive society (UNICEF, 2005).

New Zealand is a wealthy developed country, in which the majority of the population enjoy comfortable lifestyles. As New Zealand is an agricultural nation, coupled with the fact that the state provides a modest safety-net for people in need, it is often assumed that no New Zealander need ever go hungry. However, the Ministry of Health reports that more than one in five households with children sometimes or often run out of food, due to a lack of money (Ministry of Health, 2003c). As a consequence, the children in these households may sometimes eat an insufficient amount of food.

Without an adequate intake in both the quantity and quality of food, the human body and brain cannot develop to its full ability. Malnutrition in childhood is a particularly damning condition; malnourished children have lower resistance to disease and infection and are trapped in a cycle of recurring sickness, stunted growth, low energy and a reduced ability to learn. They have no hope of ever reaching their full potential. Approximately 826 million people around the world are undernourished, 34 million of whom live in the developed world (FAO, 2000).

Food is clearly more than just the means to a physically healthy life. It is also the principal avenue for participation in one's family, culture and society. For children, the preparation and consumption of food is an important developmental opportunity to participate in cultural rituals and learn about societal values.

Food is more than a 'bundle of nutrients': it represents an expression of who a person is and what they are worth, and is a focus for social exchange (Dowler, 2002:709).

Food connects us all (Riches, 2000:1). 


\section{What is food insecurity?}

Food insecurity is a pivotal ecological, economic and social justice issue for the $21^{\text {st }}$ century (Riches, 2000:1).

Food insecurity is an internationally-recognised concept that encompasses the preceding and initial stages of hunger and malnutrition, and some nutritionists would argue, also obesity. This term incorporates common perceptions of the causes of hunger (an inadequate amount of food consumed) alongside the major cause of modern malnutrition (inadequate quality of food consumed) and locates these in a society-specific context, noting that eating and sharing food is an important cultural phenomenon.

Radimer et al. (1992) define food insecurity as:

...the inability to acquire or consume an adequate quality and sufficient quantity of food in social acceptable ways, or the uncertainty that one will be able to do so.

The World Health Organisation (2004) use a similar definition and stress that for a person to qualify as food secure, their "food must be obtained in a manner that upholds human dignity."

Food insecurity can be studied at an individual, household, community or national level. At the national level, New Zealand is a very food secure country; a wide variety of foods are available at all times of the year. Most communities are also very food secure, however some ethnic groups in the population have been found to be more prone to food insecurity than others. ${ }^{1}$ It is at the household and individual level where instances of food insecurity in this country are most visible. The Ministry of Health has recognised this issue and states that New Zealand households will be food secure when everyone has "reliable access, in economic and practical terms, to the food needed for a healthy life... adequate in quality, quantity, safety and cultural acceptability" (Ministry of Health, 2003a).

\footnotetext{
${ }^{1}$ See the Literature Review page 18 for more information on ethnicity and food insecurity.
} 
Reid (1997), in her thesis which developed food insecurity indicators for use in the New Zealand Nutrition Survey, noted that a considerable number of New Zealand families experience minor food insecurity, in that they qualify under Radimer et al.'s definition of experiencing "uncertainty" that they will be able to acquire an adequate quality and quantity of food "in a socially acceptable way." Reid summarised the findings of Olsen (1994) and Radimer et al. (1990) an eight-step food insecurity continuum [see Figure 1] to adequately explain the relationship between this uncertainty - or anxiety, as she has labelled it - and hunger.

Figure 1: The eight-step household food insecurity continuum

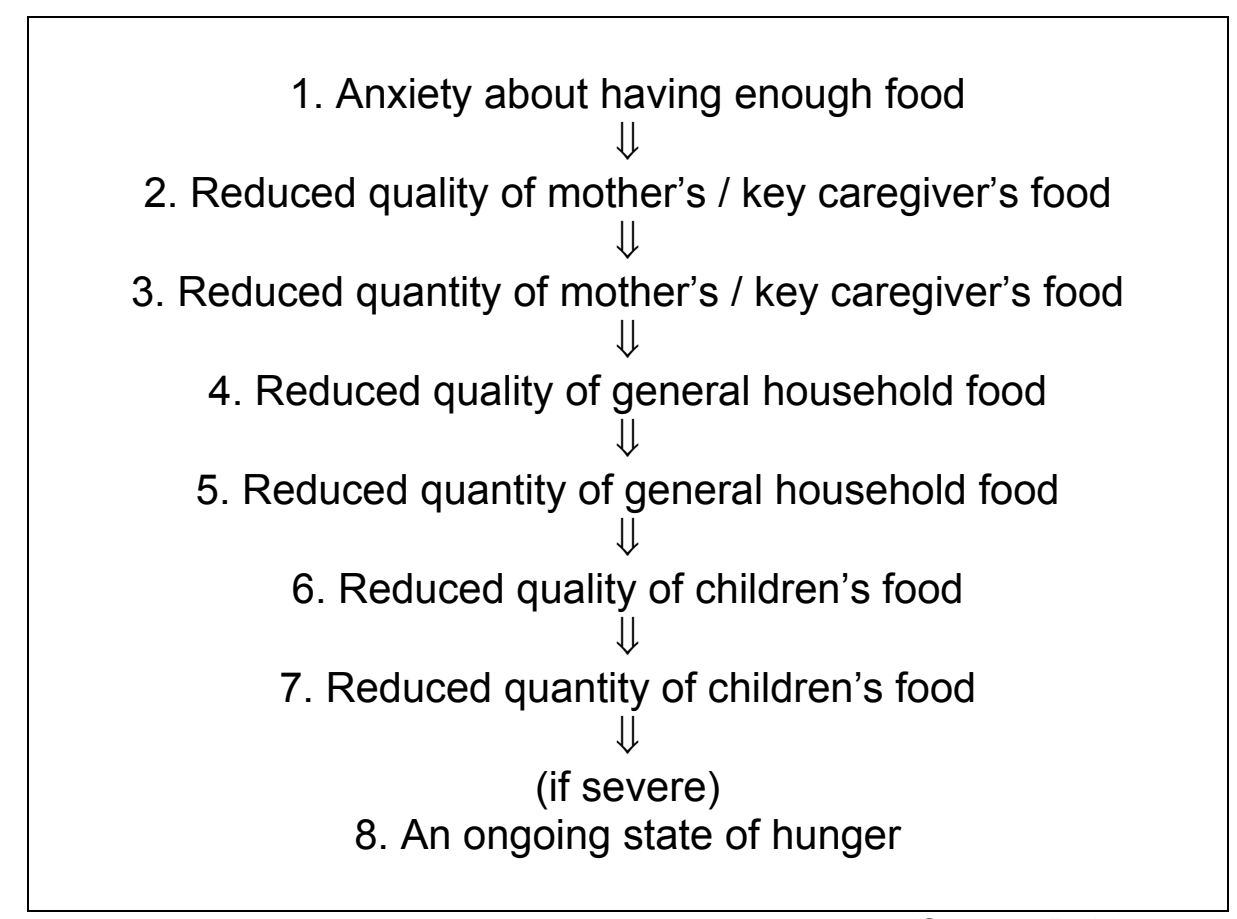

(Source: Reid, 1997)

Food insecurity researchers, including Reid (1997) and Parnell (2001), have consistently found that women feed their children before themselves. This is recognised in the continuum where the mother or key caregiver is the first in a household to experience degradation in the quality and quantity of food consumed. In her 1997 study, Parnell found that even though parents with low socio-economic status regularly went without food themselves in order to feed their children, these children still had very low intakes of nutrients, such as calcium and iron, and did not achieve the recommended intake of dairy 
products or fruit (Parnell, 1997). Even when parents deny themselves of food, their children are not necessarily safe from food insecurity.

The Ministry of Health (2004 revised ed.) has produced detailed guidelines regarding the minimum dietary requirements for children aged two to twelve. They assert that children need to eat at least the following, every day:

- 3 servings of vegetables

- 2 servings of fruit

- 5 servings of breads and cereals (including pasta and rice)

- 2 to 3 servings of dairy products

- 1 serving of meat, fish, chicken, eggs, or beans.

A serving is defined as a portion of food approximately the size of what can fit in the palm of a child's hand. Treat foods, such as potato chips, sweets, biscuits, fizzy drinks etc., are only to be eaten occasionally.

If the steps from the household food insecurity continuum which relate directly to children are applied at the individual level in the school setting, the following three-step continuum for children may be arrived at:

Figure 2: School children's food insecurity continuum

\section{Reduced quality of food}

Child brings food to school or buys food that does not meet the Children's Nutrition Guidelines [as outlined above] $\Downarrow$

\section{Reduced quantity of food}

Child has inadequate or no breakfast before school, and inadequate or no snacks/lunch during school hours

$\Downarrow$

(if severe)

\section{An ongoing state of hunger}

This continuum is a valuable tool for understanding food insecurity among children. If food insecurity can be recognised during the early stages, and there is an appreciation that this is related to the more severe form, then intervention can begin early and a serious problem prevented. 


\section{Why this research topic?}

Primarily, I was compelled to undertake research in the area of child rights and especially child poverty because, as a society, I believe we are only just beginning to comprehend our obligations toward children. Children have a weak voice in our society. They lack the political and economic power needed to protect their interests, and consequently 'adult interests' tend to dominate the political agenda. Child poverty is one of the most pressing issues of our times and any research that can contribute to our understanding of its severity and consequences is a worthwhile endeavour.

\section{Children's Rights standpoint}

If human beings have a right to life at all, they have a right to food.

Adeke Boerma

Director-General FAO, UN 1974

This research is informed by a Children's Rights framework which argues that children have three basic types of rights: provision rights, to a minimum standard of living; protection rights, safety from violence and discrimination; and participation rights, civil and political participation (Smith, 2000). This research is concerned with the first of these rights, which is addressed in Article 27 of the UN Convention of the Rights of the Child:
State Parties recognise the right of every child to a standard of living adequate for the child's physical, mental, spiritual, moral and social development... State Parties... shall take appropriate measures to assist parents and others responsible for the child to implement this right and shall in case of need provide material assistance and support programmes, particularly with regard to nutrition, clothing and housing (UNCROC United Nations).

This convention was ratified by the New Zealand Government in 1993. However, a recent report from the New Zealand Human Rights Commission states that, although most children in New Zealand are able to enjoy their basic rights, many children do not have access to "the basic necessities of life to enable them to become full and productive members of society." Most notably, this occurs when children experience poverty. The report concludes 
that "the most pressing issues to emerge are those relating to the poverty and abuse experienced by a significant number of New Zealand children" (Human Rights Commission, 2004).

\section{The gap in our knowledge about child food insecurity}

The second reason why I decided to undertake research in this area is that at present, there is limited information about the extent of food insecurity among New Zealand children. The only national study conducted with schools on this issue was nearly ten years ago, by the Food and Nutrition Consultancy Service (FNCS). Their findings estimated that 22,600 children - 3.5 percent of all New Zealand students - were regularly hungry at school, with 66,000 children regularly going without breakfast and over 21,000 regularly having no lunch at school. Many principals and teachers stated that food insecurity was an issue for some of their students.

The FNCS Survey found that over a third of schools ten years ago were providing free or subsidised food and many were taking other measures to address the problem. The FNCS recommends that more research is conducted on 'the success' of food programmes in schools, especially exploring the function of teachers and boards to see whether this role would be better performed by nutrition or health 'experts'.

The Children, Food and Poverty research updates our knowledge on the extent of food insecurity for primary school children, and explores the correlation between the socio-demographic characteristics of a community (measured by the decile rating of schools) and the level of food insecurity. This research can add to our understanding of the roles of teachers, boards of trustees, social workers and public health nurses, by examining their involvement in the policies and programmes operating in schools that respond to food insecurity. Principals' opinions are canvassed to investigate the extent to which they believe schools are responsible for providing food to children in need. 


\section{The aims and objectives of this research}

This thesis aims to explore the connections between poverty and food insecurity for primary school aged children, and to record the ways in which schools in the Wellington region respond to students who have not eaten breakfast and/or have no provision for lunch.

These aims are expressed in the following objectives of the Children, Food and Poverty thesis:

1. To measure perceived food insecurity of children in the Wellington region, in terms of:

- the number of primary school students affected

- the proportion of primary school students affected

- the relationship between food insecurity and poverty, as measured by school decile ratings ${ }^{2}$

2. To compare the responses of schools in the Wellington region to food insecurity, in terms of:

- written school policies relating to children and food

- informal school procedures for responding to children who are experiencing food insecurity

- the provision of free food to hungry children

- the use of social workers and public health nurses

3. To determine the opinions of Wellington primary school principals on:

- the difficulty for parents to provide food for their child(ren)

- the connection between food insecurity and absenteeism from school

- the role of schools in the provision of social services for children.

\footnotetext{
${ }^{2}$ See the methodology chapter page 39 for an explanation of school decile ratings.
} 


\section{Thesis outline}

The Children, Food and Poverty thesis begins with an examination of what is already known about this issue. The background/literature review opens with a consideration of child poverty in New Zealand today and then turns to the issue of food insecurity, first at the household and then at the individual/child level. This chapter concludes with an examination of how schools in New Zealand and overseas are responding to food insecurity among their students, and questions whether 'charity-based' free food programmes are solving the problem of hungry children.

The methodology chapter explains how critical realist sociology has informed this thesis, and then details the construction and use of a questionnaire for data collection. This section ends with a contemplation of possible changes and improvements which could be made to the survey design in the future.

The results chapter begins with an analysis of the schools that returned the questionnaire in order to gauge the representativeness of the responses. The chapter then follows the themes in the objectives of this project, beginning with an assessment of how many and which children in the region experience food insecurity, then documenting the responses of schools to food insecure children, and then determining principals' opinions on this issue.

The discussion section places the Children, Food and Poverty findings in the context of previous research on food insecurity and seeks to clarify whether the responses of schools to hungry children in the Wellington region are adequate to solve the problem of food insecurity.

The conclusion opens with a reflection on the significance of the results of this survey and then points out the limitations of this work and areas in need of further research. Possible strategies to solve the problem of food insecurity among children in primary schools are then explored and a variety 
of policy implications at school, community and government level are presented. This thesis concludes with the assertion that food insecurity is not an insolvable problem. All that is required to overcome this issue - and ensure that all children have the best possible start at life - is an understanding of why certain people experience food insecurity in New Zealand, combined with the political will to address the problem at its source. 


\section{BACKGROUND / LITERATURE REVIEW}

This chapter explains why child poverty has become such a pressing issue internationally and gives an overview of what we currently know about the living standards of New Zealand's poorest children. Research shows that child poverty affects nearly one in three New Zealand children and there are substantial long-tem effects when a child experiences deprivation during childhood. Following a discussion of child poverty in New Zealand, the impact of poverty on the availability of food in a household is considered, and research that provides insight into how many New Zealand children face food insecurity is reviewed. All the evidence points to children in low socioeconomic families, compounded by a non-Pakeha ethnicity, as being the least likely to get the nutritional intake they need. Finally, current knowledge on how schools are responding to food insecurity among their students is reviewed. As there is little information on this in the New Zealand context, food programmes that have been implemented in schools in the United States, Britain and Canada are considered, and their success in reducing food insecurity for children in need is evaluated.

\section{Child poverty}

Child poverty is an issue of growing concern internationally. Many developed countries have recently made commitments to reduce child poverty, recognising that for reasons of both social justice and social investment children must be a priority. Most notably, the British government has vowed to end child poverty by 2020 and has successfully managed to reduce child poverty by a quarter in the five years since the pledge was made. This reduction in the number of children growing up in poverty has been achieved primarily through increases in universal payments of family assistance and tax credits (Sinfield, 2004). 
The New Zealand government's response to child poverty has been slower and more restrained than that of Britain (Child Poverty Action Group, 2003). New Zealand's 2004 Budget has, for the first time since 1996, seen an increase in Family Support payments and the Accommodation Supplement, coupled with the introduction of an In-Work tax credit for working parents; a package collectively referred to as Working for Families, which will be phased in over the next three years. These changes will see low to middleincome families with children better off by $\$ 40$ to $\$ 150$ a week depending on their circumstances (Inland Revenue Department, 2004). Prime Minister Helen Clark asserts that these changes to the social assistance system will reduce child poverty levels by thirty percent before 2008 (Clark, 2004). However, University of Auckland economist St. John has strongly criticised the In-Work tax credit, stating that it is "designed to reward work rather than alleviate child poverty" and will continue to keep the children of beneficiaries in poverty (St. John, 2004:9).

Child poverty was the most frequently mentioned negative aspect about New Zealand as a place for children to grow-up in submissions made to the government during development of the Agenda for Children policy (Ministry of Social Development, 2002:21). This public concern with child poverty is in large part due to the emphasis successive governments have placed on economic growth at the expense of poverty alleviation. Beginning in the mid-1980s and extending through the 1990s, New Zealand experienced significant social and economic reform; welfare benefits were reduced, targeting increased, the market was liberalised, and housing, health care and education were partly-privatised (Boston, Dalziel, \& St. John, 1999). An unintended consequence of these reforms was the systematic disadvantaging of children, especially Maori and Pacific children who were over-represented in low-income households (Blaiklock, Kiro, \& et. al, 2002). Uttley (1997:107) in his study on hunger in New Zealand concludes:

The long-term effects of the decisions which have been made in the name of economic and social reform in New Zealand may offer increased material well being for some, yet they also involve a very substantial cost for others. 
At present, families with dependent children have lower Economic Living Standard Index (ELSI) ratings than the population as a whole. Twenty-eight percent of all New Zealand families have a 'very restricted', 'restricted' or 'somewhat restricted' standard of living (Krishnan, Jensen, \& Ballantyne, 2002:109). This means that nearly one-third of families lack some of 'the basics' needed for a simple New Zealand lifestyle because of the cost of these items; things such as fruit and vegetables, new clothing and shoes, a good bed and bedding, a washing machine, telephone, or heating. Children living in households with a 'restricted' or 'somewhat restricted' ELSI rating are at least twice as likely as other children to experience postponement of trips to the doctor and dentist and to lack suitable wet weather clothing. It is also at least twice as likely that books - including school books - will not be bought, computer access will be unavailable at home, and school outings and sports involvement forgone (ibid:119).

There is no official measure of poverty in New Zealand, but the government appears to have accepted the internationally-comparable measure of sixty percent of median household income, after housing costs are deducted. In 2001, 29.1 percent of children were in families below this sixty percent of median-income poverty line. This is substantially less than the peak in 1994 of 36.4 percent, but is twice the level in 1988, when 14.6 percent of children were in poor families. The families most likely to have low incomes are those reliant on income-tested benefits, sole parent families, and families with at least one adult that identify with any ethnicity other than Pakeha (Ministry of Social Development, 2004a).

Alongside the Ministry of Social Development, a non-governmental organisation - the New Zealand Poverty Measurement Project (NZPMP) has also been measuring the number of New Zealanders in poverty using an income threshold. Over the past decade, the NZPMP has held focus groups comprised of low-income householders in different regions, with differing cultures, family structures and employment categories (Waldegrave, 
Stephens, \& King, 2003). These focus groups estimated the minimum weekly budget needed for a New Zealand household; a budget that was sufficient for the family to survive 'independently' without the use of food banks or special grants. These budgets were then used to calculate the minimum annual income needed to support a family (Stephens \& Waldegrave, 2004). The income poverty threshold that the NZPMP arrived at - an absolute measurement of poverty - was approximately the same as the Ministry of Social Development's sixty percent of median household income after housing costs, which is a relative measurement of poverty. The sixty percent of median-income poverty line therefore accurately reflects the New Zealand experience of poverty; relative income poverty and absolute expenditure poverty. At any rate, UNICEF (2000:9) cautions against exaggerating the difference between relative and absolute poverty as "...most of the industrialised nations remain in approximately the same position of the child poverty league table whichever measure is used."

There are severe consequences for society if the numbers of children living in poverty are ignored, because poverty is not only damaging to a child's immediate life but also to their subsequent adult life (Brooks-Gunn \& Duncan, 1997). Smith (1998:278) states that:

...poverty during childhood... has impacts across the life span, setting off a developmental trajectory which is cumulative, affecting every conceivable kind of health outcome from mortality rates to the incidence of many kinds of illness, as well as educational outcomes.

The Dunedin Multidisciplinary Health and Development Study (Poulton et al., 2002) is the most comprehensive research in New Zealand to study the effects of childhood poverty on adult outcomes. This project has been following all of the children born in Dunedin between April 1972 and March 1973 - over 1000 children - reassessing their progress approximately every two years. They have found that low childhood socioeconomic circumstances have an overwhelmingly negative influence on adult health, "irrespective of what health cache one begins life with, or where one ends up 
in the socioeconomic hierarchy as an adult" (ibid:1650).

The Competent Children longitudinal study found that by ten years of age, children "with the least amount of family income... had significantly lower average scores for Mathematics, PAT Reading, Comprehension and Writing." This undoubtedly leads to low participation in tertiary education and reduced job opportunities later in life (Wylie, Thompson, \& Lythe, 2004:91). Waldegrave, Stuart \& King (1999) also arrive at this conclusion from their research in the New Zealand Poverty Measurement Project with low-income families:

...deprived children are less likely to experience the sort of household security and health status they require to reach their potential as effective educated and innovative members of the workforce.

It is clear from the research cited above that up to one third of New Zealand children are currently living in poverty, experiencing daily deprivation and hardships, and that this may lead to adverse outcomes for many of them in adulthood. One of the most important and common manifestations of poverty is the denial of access to the basic necessities of human existence, such as food. The incidence and consequences of food insecurity in New Zealand households will now be considered, before moving to look at research specifically about children.

\section{Food insecurity in New Zealand}

There are several myths surrounding food insecurity in Western countries. Many people find it difficult to believe that in an affluent country where the poor have access to welfare assistance, such as in New Zealand, some people are hungry (New Zealand Network Against Food Poverty, 1999). Consequently, there is a general perception that food insecurity is the fault of the individual; they must be inept budgeters, ignorant of cheap and healthy food choices, or incompetent parents. Research with low-income families 
has found that these beliefs are unsubstantiated. Several research projects in New Zealand have shown that because food is the only discretionary item in a low-income family's budget, it is the only item that can be reduced during times of financial stress (Barker \& Currie, 1994; Sadler, Rea, \& Nicholls, 1995; Waldegrave \& Stuart, 1996). Barker and Currie (1994) in their research on food insecurity in Christchurch state:

... people were unable to access food because the money that they had was insufficient to meet their needs... there wasn't enough money to manage no matter how well it was budgeted.

The claim that food insecure people are ignorant of healthy food choices is also refuted by research. The Ministry of Health has had remarkable success with its " $5+$ a day" public health campaign to encourage New Zealanders to eat more than five servings of fruit and vegetables a day, with ninety percent awareness of this advice among New Zealanders with children. This demonstrates that a lack of parental knowledge is not a principal reason why some low-income children do not eat enough fruit and vegetables (Ministry of Health, 2004:41).

In fact, the latest figures for the Household Economic Survey (HES) show that low-income households spend a greater proportion of their food budget on fruit and vegetables than wealthy households [see Figure 3]. However because the food budgets of low income households are so small, the amount spent on fruit and vegetables is still not enough to meet recommended dietary requirements (New Zealand Network Against Food Poverty, 1999). In addition, the HES also records how much money is spent on 'meals away from home' or 'ready to eat' foods. As shown in Figure 3, low-income households spend a smaller percentage of their food budgets on these types of food, contesting the claim that poor families waste their money on takeaways and fast foods. In addition, British nutrition researcher Nelson (2000:311) adds: "The prejudice that extra money in the budget [of low income families] will be spent on alcohol and cigarettes rather than food has no foundation." 
Figure 3: Weekly expenditure on food by income group of household

\begin{tabular}{|l|r|r|r|r|r|}
\hline & \multicolumn{5}{|c|}{ Annual Household Income } \\
\cline { 2 - 6 } & $\begin{array}{c}\text { Under } \\
\mathbf{\$ 2 3 , 0 0 0}\end{array}$ & $\begin{array}{c}\mathbf{\$ 2 3 , 0 0 0} \text { to } \\
\mathbf{\$ 3 7 , 8 9 9}\end{array}$ & $\begin{array}{c}\mathbf{\$ 3 7 , 9 0 0} \text { to } \\
\mathbf{\$ 5 8 , 8 9 9}\end{array}$ & $\begin{array}{c}\mathbf{\$ 5 8 , 9 0 0} \\
\mathbf{\$ 8 7 , 5 9 9}\end{array}$ & $\begin{array}{c}\mathbf{\$ 8 7 , 6 0 0} \\
+\mathbf{0 v e r}\end{array}$ \\
\hline All food & $\$ 69.95$ & $\$ 102.80$ & $\$ 130.45$ & $\$ 173.60$ & $\$ 235.30$ \\
\hline Fruit & $\$ 5.70$ & $\$ 7.10$ & $\$ 8.00$ & $\$ 10.45$ & $\$ 14.20$ \\
\hline Vegetables & $\$ 6.20$ & $\$ 8.25$ & $\$ 9.30$ & $\$ 12.40$ & $\$ 15.35$ \\
\hline $\begin{array}{l}\text { Food budget } \\
\text { spent on fruit } \\
\text { and vegetables }\end{array}$ & $\mathbf{1 7 \%}$ & $\mathbf{1 5 \%}$ & $\mathbf{1 3 \%}$ & $\mathbf{1 3 \%}$ & $\mathbf{1 3 \%}$ \\
\hline $\begin{array}{l}\text { Meals away } \\
\text { from home }\end{array}$ & $\$ 11.75$ & $\$ 18.40$ & $\$ 32.55$ & $\$ 45.00$ & $\$ 76.25$ \\
\hline $\begin{array}{l}\text { Food budget } \\
\text { spent on meals } \\
\text { away from home }\end{array}$ & $\mathbf{1 7 \%}$ & $\mathbf{1 8 \%}$ & $\mathbf{2 5 \%}$ & $\mathbf{2 6 \%}$ & $\mathbf{3 2 \%}$ \\
\hline
\end{tabular}

Data source: HES Year ended 30 June 2004 (Statistics NZ)

It is understandable that some low socio-economic families in New Zealand have difficulty buying food. At present, a single parent on the Domestic Purposes Benefit with a 10 year old child living in Wellington receives $\$ 357.12$ a week from Work and Income New Zealand ${ }^{3}$. With an average rental accommodation cost of $\$ 240^{4}$ deducted from this benefit payment, $\$ 117.12$ remains for food, phone and electricity bills, transportation, insurance, clothing, and debt repayments. Nutrition researchers at Otago University report that a woman with a 10 year old child living in Wellington needs to spend $\$ 88$ a week on food in order to attain the basic minimum amount of food required for a healthy diet for them both (Department of Human Nutrition, 2004). Bearing in mind that food is likely to be the only flexible item in this weekly budget, the above family is an example of a household who may find it difficult to be food secure.

Food insecurity researchers Dreze and Sen (1995:22) state that there is an irrefutable "interconnection" between hunger and poverty. After studying food insecurity throughout the developing and developed world, they conclude that low economic status is a predictor of food insecurity and that the observation of food insecurity is an indicator of poverty. Certainly in New

\footnotetext{
${ }^{3}$ Main benefit (\$235.12) + Family Support (\$47) + Accommodation Supplement (\$75). Information obtained from WINZ website www.workandincome.govt.nz/manuals-andprocedures and confirmed on the telephone, phone 0800559 009, on 9 February 2005. ${ }^{4} 2003$ figure, from www.bigcities.govt.nz/housing.htm
} 
Zealand, where there is an abundance of healthy food choices, food insecurity is strongly linked to poverty. The Ministry of Health (2003c:16) states:

....in the poorest income groups, food acquisition is sensitive to both price and income, and many people struggle to obtain enough high-quality food to achieve what is considered to be a healthy diet.

There is a limited body of research exploring the extent of food insecurity in New Zealand households. The 1997 National Nutrition Survey (Ministry of Health, 1999) found that thirteen percent of New Zealanders can only afford to eat properly sometimes, while fourteen percent of households sometimes run out of food because of a lack of money, and two percent of households often run out of food. Parnell et al. (2001) note that more New Zealand adults experience food insecurity than those in either the United States or Australia.

The use of charitable foodbanks or food grants from Work and Income New Zealand (WINZ) is a very clear indicator of food insecurity among households. Relying on others for food is not regarded as normal practice in New Zealand and it therefore breaches the definition of food security according to the World Health Organisation who state that "food must be obtained in a manner that upholds human dignity" (2004). Riches (2002:658) argues that foodbanks are socially unacceptable world-wide, and quotes Canadian research which found "the vast majority (84 percent) of women described feeling shame, embarrassment, degradation and humiliation at their first visit to a foodbank."

Approximately 300,000 New Zealanders a year receive a Food Grant or an advance on their benefit - a recoverable debt - in order to buy food (Ministry of Social Development, 2004b). Food grants and advances are not easy to obtain. WINZ require proof that the hungry person does not have any money or assets, that they have exhausted all other options, justification of why they are in a situation that requires assistance, and proof that they did not cause or contribute to their situation (ibid). 
The New Zealand Council of Christian Social Services (NZCCSS) has monitored foodbank use at seven foodbanks four times a year since 2000, and state that there is evidence of "an entrenched underclass" in New Zealand. They have consistently found these characteristics to be common to foodbank users: households with children, benefit-only incomes, high debt, rental housing and high housing costs relative to income (NZCCSS 2004). In 1996, the Coalition of Wellington Region Foodbanks (1996:7) stated that they were aware that foodbanks were one of the most "demeaning and demoralising tools in society" but pointed to the fact that:

Foodbanks were set up as a short-term measure. Without wanting to do so, they have now become part of the fabric of New Zealand. They [the foodbanks] have seen little evidence that the economic restructuring, meant to benefit the whole of society, has indeed delivered what it promised to those on the lower end of the scale.

In 1999, the New Zealand Poverty Measurement Project - in conjunction with the work it undertook on poverty measurement, mentioned earlier in this chapter - surveyed 401 low-income New Zealand households to identify the particular problems they faced, the support they received and other issues related to poverty. Forty-nine percent had been unable to provide a meal for their family at least once in the previous three months because they could not afford it. Twenty-eight percent had been unable to provide four or more meals in the previous three months for the same reason. Ethnic differences were pronounced: 72 percent of Pacific households, 48 percent of Maori households and 38 percent of Pakeha households had been unable to provide a meal for their family. Eighty percent of the households surveyed said that the variety of foods they were able to provide for their family was limited because of a shortage of money; 31 percent said it was 'always limited.' Twenty-four percent of respondents had used a foodbank. Waldegrave et al. (1999) conclude that many low-income New Zealand households are substantially deprived of essential household items and services, and that the impact of poverty is disproportionately felt among Maori, Pacific peoples, women and children. They stress that difficulty 
ensuring the regular consumption of essential foods has nutritional consequences for people's health and education: "The future social impacts of this are likely to be severe in view of the high proportion of children living in poverty" (ibid).

While the above research has been conducted on food insecurity in households generally, there have only been two published research projects specifically about New Zealand children and food insecurity: the 1995 Public Health Commission on the Perceived Food Inadequacy Among Children in Schools and the 2002 National Children's Nutrition Survey. Both reports find that food insecurity for children is strongly associated with low socioeconomic status.

In 1995, the Food and Nutrition Consultancy Service at Otago University was commissioned by the Public Health Commission to conduct a large quantitative research project on the issue of hungry children in schools. Their aim was to discover the extent of hunger among school children as perceived by teachers, and document the provisions currently within schools to address the problem. Questionnaires were sent to all New Zealand primary, intermediate and secondary schools and a response rate of 85 percent was obtained, no doubt reflecting the high level of interest in this issue among Principals. The results estimated that 3.4 percent of children in New Zealand were regularly hungry (22,605 children), 9.1 percent went without breakfast $(66,018$ children), and 3.2 percent had no provision for lunch $(21,152$ children). Analysis of the data indicated that school size had little to do with either the numbers of children estimated to be hungry, those that had not had breakfast, or those with no lunch. However, private schools and integrated schools reported a much lower number of students experiencing food insecurity. Regional differences were very noticeable, in line with the socio-economic status of each region. Auckland City, South Auckland and the Hutt Valley had much higher levels of estimated hungry children than other areas in New Zealand. South Auckland and Northland had the highest proportion of children having no breakfast before school. 
Auckland City, South Auckland, the Hutt Valley and South Waikato reported the highest rates of children having no provision for lunch (Food and Nutrition Consultancy Service, 1995).

The FNCS project did not attempt to correlate the existence and extent of food insecurity with poverty. At the time of the FNCS research, schools were not assigned decile ratings by the Ministry of Education as they are today. The FNCS researchers could not easily distinguish those schools serving low socio-economic communities, and instead focussed on the ethnicity variable. They found that the higher the percentage of Maori and/or Pacific children at a school, the greater the food insecurity measured with all three indicators (children estimated to be hungry, those that have not had breakfast and those with no provision for lunch).

The second national research on children and food insecurity in New Zealand - the 2002 National Children's Nutrition Survey - was funded by the Ministry of Health and conducted by the University of Auckland, Massey University and the University of Otago. This project recruited 3,275 children to form a nationally-representative sample with which to study all aspects of the nutritional status of New Zealand children. This research used a combination of methods: anthropometric measurements, blood and urine samples, interviews with the parent/caregiver, 24-hour diet recall, and questionnaires. The main findings were that younger children have better food and nutrient intakes than older children and were less likely to be overweight or obese. Also, Pakeha children were most likely to have an adequate dietary intake and be in a healthy weight range (Ministry of Health, 2003c).

In regards to household food security, results from the Children's Nutrition Survey were slightly worse than the Ministry of Health's earlier research in 1997 due to the fact that the participants of this project comprised only households with children who have, on average, a lower socio-economic status than households without children. Twenty percent of households in 
this research said they could only sometimes afford to eat properly; 22 percent reported that food runs out because of a lack of money sometimes or often (often in 3.6 percent of households), 18 percent of households said they eat less because of a lack of money sometimes or often. Maori and Pacific households are much more likely to face food insecurity; over half (54 percent) of Pacific households run out of food sometimes (44.2 percent) or often (6.2 percent). Not surprisingly, the poorest households in the sample were also the most likely to face food insecurity (Ministry of Health, 2003c:109).

The National Children's Nutrition Survey also collected information about children's eating habits, recording when and where they consumed food. The large majority of New Zealand children (aged 5 to 14 years old) eat both before and during school hours, but there is a minority of children who do not. Nearly 4 percent of children in this study did not consume any food before school and 1.4 percent did not have any food during school hours over a one-week period (Ministry of Health, 2003c:118). These figures rise when looking solely at children from the most deprived households, measured using the New Zealand Deprivation NZDep Index (constructed by Crampton, Salmond, Kirkpatrick, Scarborough, \& Skelly, 2000). In NZDep01-V households (the bottom 20 percent of households), 5.5 percent of boys and 8.6 percent of girls had not had any food before school and approximately 2.5 percent of all children in these households had not had any food during school hours over the whole week-long period (Ministry of Health, 2003c).

These statistics, which prove the existence of food insecurity among children in New Zealand, become deeply concerning when the effects of food insecurity are considered. The consequences of poor nutrition during childhood have been well documented worldwide. As mentioned briefly already, children who do not receive the appropriate amount or quality of food often experience poor cognitive development, decreased energy levels, behavioural problems, and a variety of health problems later in life (Centre 
on Hunger Poverty and Nutrition Policy, 1995; Leather, 1997; Pollitt, 1993). American researchers, Alaimo, Olson and Frongillo (2001) found that even after adjusting for other possible factors, children aged 6 to 11 years that did not eat sufficient food had significantly lower math scores, were more likely to repeat a grade, and had difficulty getting along with others, than children who ate well. A British study (Nelson, 2000) reported that children aged 5 to 18 years from low socio-economic families had considerably low iron, calcium, folate and other nutrient intakes, which led to high rates of anaemia, low intelligence, reduced activity and low bone mineral density. Parnell (2001:142) states:

Food insecurity eventually puts physical health at risk through malnutrition and can jeopardise emotional and social wellbeing. Even periodic episodes of food insecurity are undesirable and could contribute to weight cycling and obesity.

Sometimes children do not go to school when there is insufficient food for their lunch because their parents are worried that they will be teased or welfare professionals will be alerted. Reid's focus-group research, in which food insecurity was discussed with low-income New Zealand women, supports anecdotal stories from teachers that this occurs (Reid, 1997:55). Two women in her focus groups stated:

I keep my college kid at home if I have no food for her lunch. It's too embarrassing for her in front of her friends not to have any food.

I have kept my kid at home from school for days as I couldn't afford to give him any lunch. I felt degraded and we were all depressed and grumpy.

Not providing food to a child in your care is a form of child maltreatment and is commonly categorised as neglect by welfare services. Food insecurity can therefore result in serious consequences for the parents of a child suffering from food insecurity when welfare professionals are alerted. However, a systematic review of the literature on the abuse and neglect of children conducted for the Department of Child Youth and Family Services (Saville-Smith, 1999:29) found that poverty was the common factor in the 
vast majority of families where neglect of children occurs. In fact, SavilleSmith stresses that poverty is more closely correlated with neglect than it is with abuse in families. The Department of Child, Youth and Family Services (2001:23) state:

Parents may neglect to provide physically for their children but not to the point of malnutrition. Such children are frequently hungry but continue to grow. School performance will often suffer in such circumstances and children may turn to neighbours or theft to obtain food.

The government is clearly concerned about the presence of food insecurity among children in New Zealand. In 2003, the Ministry of Health released a new policy Healthy Eating, Healthy Action: A Strategic Framework (2003b). In this publication, the top two priorities listed for the Ministry are the food needs for "lower socio economic groups" and "children and their families." The Ministry of Health states that, alongside growing obesity, New Zealand has a food security problem because people on low incomes struggle to afford the high-quality food they need for a healthy diet (ibid). In the Implementation Plan of this strategy, published in June 2004, the Minister of Health asserts that a wide range of government and non-government agencies must be involved in a coordinated response to poor nutrition, inactivity and obesity (Ministry of Health, 2004). Schools are recognised as a central "supportive environment" in the Implementation Plan and there is increased funding to investigate a Fruit in Schools programme and to "expand other evaluated successful education setting initiatives, for example, breakfast programmes..." (Ministry of Health, 2004:22).

\section{School responses to food insecurity}

While showing concern about the level of food insecurity among children in New Zealand, there have been no policies or programmes organised at a national level to address the issue of hungry children in schools, since the school milk scheme which was stopped in the mid-1960s after nearly 30 years of providing government-subsidised milk everyday to school children 
(NZ Milk Board, 1966). The Food and Nutrition Consultancy Service (FNCS) research (1995) recorded that some schools ten years ago did provide free food to children in need, however, the programmes were generally selffunded or organised in collaboration with community groups.

The FNCS research (1995) established that 38 percent of schools throughout New Zealand supplied free or subsidised food either sometimes or on a regular basis. Those schools providing free or subsidised food were nearly all large (with more than 160 students), state schools in KapitiPorirua, Auckland City, South Auckland, Hamilton City or the Hutt regions. The Wellington region (Kapiti, Porirua, the Hutt Valley, Wellington city and the Wairarapa) had over half of all schools supplying food sometimes or daily. The higher the percentage of Maori or Pacific children in the school, the greater the likelihood that the school provided free or subsidised food. However, only 15 percent of New Zealand primary schools received financial assistance or donations of food from the community to deal with the issue of hungry children. Nearly 30 percent of schools throughout New Zealand were taking "some other action" to address the issue of hungry children in their schools, such as contacting a public health nurse, support services, or counsellors when the need arose.

In addition to the FNCS project, there has been significant popular press coverage of the responses by schools to the perceived need for food security. Fowler and Schmidt, in an article for Metro (1994), highlighted the issue of food insecurity in South Auckland by describing a variety of responses of schools to hungry children, from operating a 'shared-lunch system' through to substantial free food programmes with community involvement. In a recent article in The Wellingtonian (Saunders, 2004b), the principal of Newtown School in Wellington city shared the experience of his low decile school. He stated that breakfast and lunch are provided to about three or four children every day that are in need, organised by a teacher aide and funded solely by the school; "It really affects their learning. If they haven't had breakfast and lunch, then food is all they think about." $\mathrm{He}$ 
concludes after speaking to parents about the issue that the situation usually arises when a family member loses their job or unexpected bills come up (ibid). A newspaper article in the Dominion Post (Saunders, 2004a) reports that the principal of Naenae School in Lower Hutt, in collaboration with Wellington Regional Public Health, conducted a survey and found that more than one in ten children were coming to school without having eaten breakfast. Another unnamed primary school principal comments that her school regularly supplies food: "It's not expensive but... it's money that doesn't go into other things" (ibid).

A small number of food programmes in schools operate at a local level throughout New Zealand. Manukau City Council has been instrumental in collaborating with schools and community groups to implement the 'Food in Schools' programme for children in need, which has been operating for over ten years. Currently, this programme provides 1300 meals every school day throughout 41 schools in South Auckland (Te Ora o Manukau - Manukau the Healthy City, 2003). The Manager of the Trust providing the meals, Heather Smith, explains that the need for the service is growing; "There is hunger in the schools here. I get calls from schools all over New Zealand who need our support... in the past five months, five more schools have joined the programme" (Farrell, 2003).

\section{Research on food programmes in schools}

While responses to hungry children in New Zealand have been generally short-lived and regional-specific, many western countries (most notably Britain and the United States) have had national free or subsidised food programmes in schools since the end of World War II when child malnutrition rates were high. However, increasing targeting and means-testing of social services under a neo-liberal political agenda in the 1990s has seen the rate of 'take-up' among eligible children fall, alongside declining eligibility. A lack of funding for free food programmes is not an issue in these countries, yet their food programmes appear to have had limited success. 
Child Poverty Action Group (UK) state that although there are 2.8 million children aged 5 to 16 years living below the poverty-line in England, only 1.8 million of them are eligible for a free school meal (McMahon \& Marsh, 1999). In addition, Storey and Chamberlin (2001) state that approximately 20 percent of these 1.8 million 'eligible' children currently do not take-up their entitlement. Their qualitative study involving thirteen schools in low socioeconomic areas found that a third of students and over two-fifths of parents believed that embarrassment or fear of being teased were the main reasons people decided not to take-up the free meal. In schools where students had to identify themselves, either by giving their name or by producing tickets for their meals, many of the children suffered embarrassment. Two of the schools with large canteens had 'cash-less' systems where all students used a swipe-card to purchase their meals, providing recipients of a free lunch with anonymity. In schools where lunch was only provided for 'those in need', many parents decided not to use the service because free meals came in recognisable packaging and were stored separately from other children's lunches. Parents were very concerned about possible stigma for their children. A further eleven percent of parents from schools participating in the research did not even know their child was eligible to receive free school meals (Storey \& Chamberlin, 2001).

The Evidence Network in London has conducted a systematic review of the research on breakfast and 'free fruit' programmes in both American and British schools (Lucas, 2003). This review found that breakfast programmes are nearly always positively evaluated as they are associated with improved nutrition, better academic performance, improved concentration, increased school attendance and improved behaviour at school. Both types of programmes are found to have positive social as well as nutritional outcomes, providing children with a safe place to socialise. However, there is no evidence that free food schemes reduce health inequalities, as most of the research cited concern about the low participation rates of those in most need due to the stigma associated with targeting (Lucas, 2003). 
Raine, Mclntyre and Dayle's qualitative research in nine Canadian schools where six breakfast and three lunch programmes were operating - also found that fear of stigmatisation was preventing the programmes from attaining their goal of providing food to hungry children (Raine, Mclntyre, \& Dayle, 2003). As in New Zealand, Canada does not have any nationally funded food programmes in schools and therefore they are generally volunteer-run, donation-funded and heavily targeted to those in need. Raine et al. found that non-attendance of food programmes was strongly correlated with ethnicity; white children in need were not using the programmes. In one of the poorest schools in their study, which had the lowest participation rate (2 percent), the organiser commented, "I think there is an underlying feeling that the community will lose face because they have hungry children" (ibid:162). Raine et al. note that it was the parents rather than the children who worry most about stigmatisation, especially the fear of assumed neglect. These fears are validated by documentation of the stereotypical assumptions of the programme volunteers and coordinators, one of whom commented that the parents of children attending the programme squander their welfare benefit; "they drink, they play bingo, they smoke it up or they booze it away" (ibid:162). Raine et al. conclude that the 'charitable-model' of providing food to hungry children is "... alienating, contributing to resistance by families who fear stigmatization and could benefit most from supplemental food" (ibid:165).

Riches (2002) argues that the charitable model for food programmes is inappropriate and ineffective. He states that charitable food programmes (both foodbanks and free school meals) have legitimacy because they provide emergency relief as well as an outlet for people to be altruistic. However, they keep hunger out of public debate by providing the "illusion of a solution." Hunger has become a private and personal problem, where the individual is seen to be at fault, and it is therefore no longer the responsibility of the state or the community to ensure that no one is hungry. Hunger is depoliticised as a matter of charity, rather than being interpreted an issue of 
social justice, and consequently public money is not spent on its eradication (Robinson, 2002).

Riches (2002) and Raine et al. (2003) argue that instead of charity, food programmes should be based on a social justice model, which supports and empowers families to analyse the root causes of food insecurity so that community resources can be better allocated toward addressing the problem. They assert that when social justice principles are applied to the specific issue of hungry children it is clear that poverty reduction is the only solution:

...a social justice perspective would ensure that families have sufficient economic resources to fulfil their basic needs, including essential nutrition for all members... the charitable discourse of the public, content to see that 'hungry children' are being fed by well-meaning volunteers through communitybased feeding programmes, would be replaced by a repoliticized discussion of whose needs are being served and at times ill-served by their proliferation (Raine et al., 2003). 


\section{METHODOLOGY}

\section{Research design}

The Children, Food and Poverty thesis is underpinned by a critical realist theoretical perspective. Critical realism argues that a material reality exists outside of our representations of it, but knowledge is historically and culturally situated so reality cannot be objectively represented (Archer, 1995). Critical realists are therefore 'objectivists' in an ontological sense, but they reject positivism - the idea that research can uncover the objective truth - because all knowledge is relative.

Roy Bhaskar is the founder of critical realist sociology. He explains that positivism is flawed because it commits the "epistemic fallacy" of reducing being into knowing, that is, reducing ontological questions into epistemological questions. In positivism, "what exists, and what is knowable, is defined solely in terms of how we have knowledge" (Cruickshank, 2003:96 emphasis in original). Bhaskar argues instead, that knowledge is "conceptually mediated, and that this knowledge is of an external reality which cannot be known with epistemic immediacy" (ibid:98). This means that any claims to knowledge are fallible. In relation to this project, I have attempted to determine the extent of food insecurity amongst children in the Wellington region, but this claim is merely an attempt affected by my historical and cultural situation - to explain reality.

Critical realists also take issue with the subjectivism found in postmodernist thought, because this epistemological standpoint negates the existence of any concrete reality. Critical realists Lopez and Potter (2001:9) state this succinctly: "Truth is relative to be sure but there is still both truth and error, as well as lies!" Subjectivism holds that individuals construct their own reality, and this does not allow for a collective, macro-social interpretation of issues. Lopez and Potter explain that "postmodernist writing celebrates ambiguity and complexity, while realism struggles for clarity and simplicity" 
(2001:5, emphasis in original).

Critical realism is intent on explaining reality so that society can move toward solutions to our seemingly intractable problems. It includes the pragmatism of positivist approaches, while maintaining the critical nature of subjectivism (Robson, 2002:41). Porpora (2001:266) concludes: "Alone today, critical realism affords a philosophical foundation for an emancipatory politics."

Critical realists frequently employ methods that are usually considered positivist, as they are, in essence, methodological pragmatists. Porpora (2001:262) justifies this seeming anomaly: "positivism mistakenly conflates evidence and explanation, but there is no reason for realism not to disentangle the two... rather than being explanatory tools, analytical statistics - including regression - are evidentiary tools, enabling assessment of explanations." For the Children, Food and Poverty research, a traditionally 'positivist' method - a survey questionnaire - has been employed, but it is confined within the critical realist perspective outlined above. The data collected and the statistics produced from this research are simply evidentiary tools, rather than evidence, to assist in assessing the situation in Wellington schools.

In line with critical realism, this research project uses a survey design for largely pragmatic reasons. There is little information in New Zealand for policy makers to utilise when making decisions regarding food insecurity and children. There is no over-all picture of the situation in schools; there is a lack of knowledge both of how many schools are instigating policies and programmes regarding food insecurity, and how these programmes are operating. A survey allows for a large number of schools to be included in the study, while also enabling assessment of the variety of responses to food insecurity within schools.

The questionnaire used in this research includes both closed (fixed-choice) and open-ended questions. The data collected from the closed questions 
allow for comparisons between the schools and for ease of statistical analysis. The answers obtained from the open-ended questions add a qualitative aspect to the statistics generated, allowing for a more in-depth analysis of the situation in schools. It was important to include space for principals to give their opinions and thoughts on this issue; they are in a unique position to provide insight into both the extent and effects of food insecurity among children, and many of them are actively working to find solutions to this issue.

Figure 4: A diagrammatic representation of the research design (based on Crotty, 1998:4)

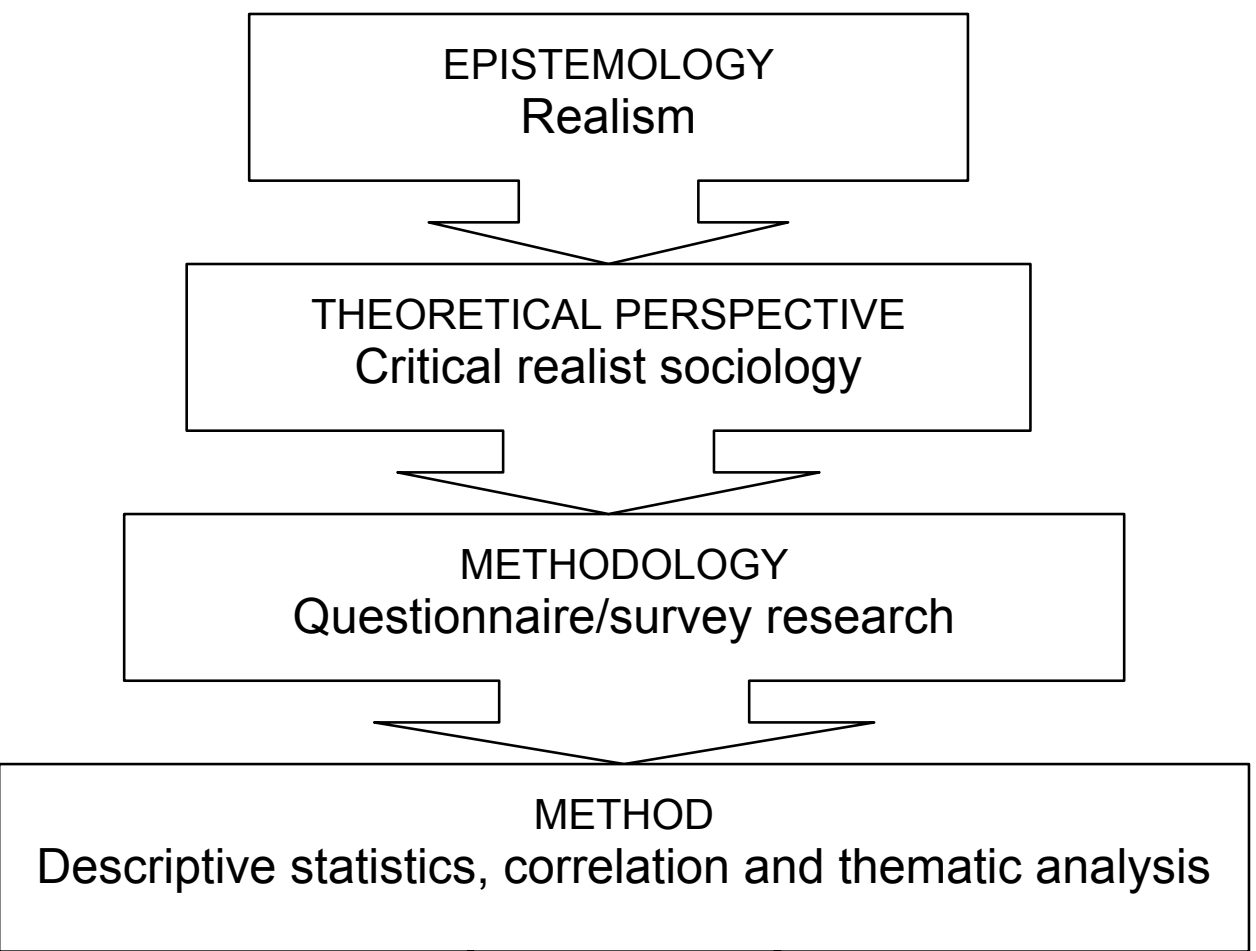

The data collected in this research are descriptive in nature; they describe the characteristics of children and schools in the target population. They are not inferential and, therefore, are not representative of the situation in all of New Zealand. In order to obtain inferential data, this research would have to have used a sample of schools drawn from the whole country. Instead, this project comprehensively describes the situation in the Wellington region at a particular point in time, May 2004. 
The wider Wellington region was chosen for this research for a few reasons. First, Wellington contains a cross-section of the different types of communities found throughout the rest of the country. It consists of both rural and urban areas, each including schools with a wide range of decile ratings. Some of the most affluent and some of the poorest people in the country live in Wellington. It contains communities with high proportions of Maori and Pacific children, and other areas which lack ethnic diversity. While, the statistics produced from this research cannot be representative of the whole of New Zealand, the diversity of the population in the Wellington region will result in a greater understanding of the variety of responses schools have to the issue of food insecurity.

Given the suspected link between poverty and food insecurity, the inclusion of the Wairarapa communities in this research is timely. There has been intense media coverage of the Wairarapa region over the past year, following the murder of six-year old Coral Burrows of Featherston, who died of head injuries inflicted by her stepfather. This case highlighted, amongst other issues, the extreme poverty of many people in the Wairarapa and the stress poverty places on families.

As I have lived in Wellington city for many years, I feel an affinity with the communities of this region. I was originally drawn to the issue of hungry children in schools when reading a newspaper article on the work of Manukau City's 'Food in Schools' programme (Farrell, 2003). Noting the support this programme enjoys from the Manukau City Council, I wanted to investigate why same initiatives were not occurring in my community.

I have decided to focus on primary school aged children, Year 1 to 6 , for two reasons. First, while working as an Early Childhood Teacher before returning to university, I was acutely aware of the importance of nutritious food for the development of young children's minds and bodies. As shown in the literature review, countless articles link poor nutritional status with 
stunted growth and low intellectual ability, and I observed how children with inadequate diets were unhappy and unwell, lacking the concentration and stamina needed to learn. The childcare centre where I worked provided healthy snacks and lunch everyday for the children in our care, yet a few parents commented to me that the lunch we provided "was the only hot meal [their child] received during the day". Second, there is the possibility that some children do not eat breakfast and lunch for reasons other than poverty, most notably mistaken dietary concerns and eating disorders. In order to minimise the likelihood of these issues affecting the research, students above Year 6 have been excluded.

Parental neglect may also be a factor behind children arriving at school without having eaten breakfast and with no provision for lunch. This topic is briefly discussed in the previous chapter, ${ }^{5}$ however, there has been no provision to analyse neglect of children in this research. Essentially the Children, Food and Poverty research is not concerned with the specific reasons why children are hungry, but rather, it aims to quantify the number of hungry children, describe which schools are more likely to have children affected by food insecurity, and detail the policies and procedures that have been, or should be, put in place to respond to food insecurity.

\section{Data collection and analysis}

Data were collected for this research through a self-administered questionnaire sent to the principals of all 188 schools in the target population. This research included all State and Integrated schools that teach children in Years 1 to 6 (Full Primary, Contributing and Composite schools) in the Wellington region, as defined by the Ministry of Education. The Wellington region includes Wellington city, Tawa and Johnsonville, Porirua, the Kapiti Coast (including Otaki), Lower and Upper Hutt, Wainuiomata, Masterton, Carterton and South Wairarapa [see Figure 5].

\footnotetext{
${ }^{5}$ See the Literature Review page 22 for research on the role of neglect in cases of food insecurity among children.
} 
Figure 5: Map of the Wellington region showing district areas used by the Ministry of Education

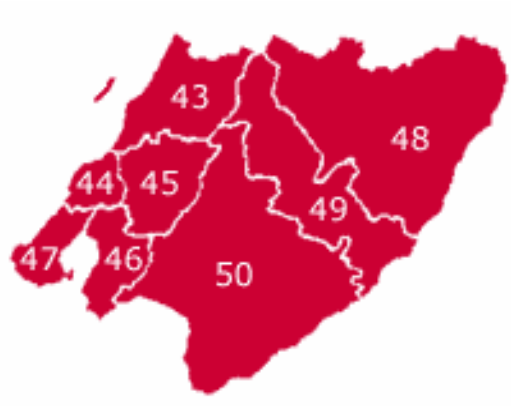

Key:

43. Kapiti Coast District

44. Porirua City

45. Upper Hutt City

46. Hutt City

47. Wellington City

48. Masterton District

49. Carterton District

50. South Wairarapa District

The names and decile ratings for each school in this target population were obtained from the Ministry of Education's website ${ }^{6}$ and the physical and email addresses for the schools were from Te Kete Ipurangi - The Online Learning Centre ${ }^{7}$. There was some discrepancy between the data on these websites; ten schools had closed and two had opened since the 2003 data was entered on the Ministry of Education website. Once these changes were accounted for, there were 188 schools in the target population. The most recent decile ratings for the schools at the time of research were the 2003 deciles, however, three schools in the sample did not have decile ratings assigned to them in that year, and so their 2002 decile ratings were subsequently used.

Prior to posting the questionnaire, the schools were sent an email or a letter if email was unavailable outlining the research project and stressing the importance of their participation [See Appendix 1 for the email]. The questionnaire was sent on 1 June 2004, with a cover letter and a prepaid envelope for returning the questionnaire [See Appendix 2 for the cover letter].

The questionnaire itself was partly modelled on the Food and Nutrition Consultancy Service (FNCS) survey, which was sent to principals of all primary, intermediate and secondary schools throughout New Zealand in 1995. Questions concerning the measurement of food insecurity (Q1-4) were

\footnotetext{
${ }_{7}^{6}$ www.minedu.govt.nz/goto/deciles

${ }^{7}$ www.tki.org.nz/e/schools
} 
similarly worded, to allow for comparability with the original findings. For example, "Thinking about the last month, that is the month of May, how many children do you estimate came to school without breakfast on a regular basis?"

However, questions concerning the responses of schools to perceived food insecurity (Q5-8) were reworded and expanded upon. The FNCS questionnaire set out to quantify the extent of food insecurity. It failed to give schools the opportunity to explain in detail their responses to this issue as it only requested the numbers of children receiving free or subsidised food and whether 'anything else' was being done to address this need. This research goes into greater depth than the FNCS survey and therefore included questions on:

- the existence and wording of written policy in the school for dealing with children who have not had breakfast and/or have no provision for lunch

- the informal procedures teachers may have for dealing with children who have not had breakfast and/or have no provision for lunch

- the existence of free food programmes in the school

- how the free food programmes operate in practice (human and financial resources)

- the use of Social Workers and Public Health Nurses in dealing with this issue

- and their opinion on the issue of children and food insecurity

The FNCS survey distinguished between free and subsidised food, asking separate questions regarding whether the school provided free food or subsidised food to hungry children. This research only includes questions on the provision of free food in schools for two reasons. Firstly, the FNSC had a poor response rate for the question on subsidised food, presumably because most schools do not provide subsidised food. Secondly, the FNSC found that the provision of subsidised food was more likely to occur at secondary 
schools, whereas primary schools were more likely to provide free food (FNCS 1995:47-55).

The questions in the FNCS survey regarding the purchasing of food by children (Q9-11) were also omitted from the questionnaire as they are extraneous to the objectives of the Children, Food and Poverty research and detract from the issue.

The questionnaire ends with a similar question to that of the FNCS survey (Q12) allowing respondents to add any further comments they have on the issue of children, food and poverty [see Appendix 3 for the questionnaire].

The majority of completed questionnaires arrived in the first two weeks after they had been posted. Three weeks after the mailout, a reminder postcard was sent to the 80 schools that had not yet returned their questionnaire, assuring them that their participation was still needed and valued [see Appendix 4 for reminder postcard]. Finally, one month after the questionnaire was mailed, I telephoned schools that still had not returned their questionnaires. At this point, if they had lost the original questionnaire, another one was posted to them with a prepaid return envelope enclosed.

Unfortunately, I was unable to speak directly with the majority of principals when I phoned schools, as it was the week of the National Principals' Conference. When I could not talk to the principal a message was left with my contact details, or in most instances I could speak with the Assistant Principal. Some of them raised concerns about my motivation for conducting the research (was I suggesting schools should be providing food? Was this poor-parent bashing?). In most instances, once I had explained my background, they requested that another questionnaire was posted for them to complete. Three low decile school Principals commented that the questions were too difficult for them to answer, especially the first page asking for estimates of numbers of hungry children; "There are just too many [hungry children] for us to give you an accurate number" was one principal's comment. Two principals suggested that if they had been asked to keep a 
record for the coming month of students who arrived at school without having eaten breakfast and had no provision for lunch, rather than retrospectively asking for an estimate, they would have been happy to participate.

Dillman (2000) lists four types of common errors that should be avoided in survey research regarding sampling, coverage, measurement and nonresponse. Sampling error, where an important element of a population has not been included in the sample, is not a concern for this research because the whole population was included in a census of all Wellington State and Integrated primary schools. Coverage error was also not a problem. This is when the members of the survey population do not have an equal chance of inclusion in the research. As the names and addresses of schools were obtained from the Ministry of Education, the whole population was easily accessible and therefore included in the research.

However, measurement error and non-response error were important considerations in the design of this questionnaire. Measurement error occurs when a respondent's answers are inaccurate or cannot be compared to other respondent's answers. This usually happens when questions have been worded inappropriately. I sought expert feedback on the questionnaire after it was designed, and conducted a pre-test of the questionnaire involving a principal of a school outside the Wellington region, to mitigate the likelihood of measurement error.

Non-response error is the result of a difference between the people who have responded to the survey and those who did not, when these characteristics are important to the study (Tolich, 2001). This could have occurred in this research had few principals from low socio-economic decile schools returned questionnaires, and I had subsequently been unable to correlate the incidence of food insecurity with schools servicing poorer communities. The likelihood of non-response error has been minimised by emphasising the importance of each school's participation in the letter accompanying the questionnaire and in the follow-up correspondence. The returned 
questionnaires were analysed to ensure that non-response error is not an issue. $^{8}$

The Children, Food and Poverty research has been guided by the general principles of the Human Ethics Committee at Victoria University of Wellington. $^{9}$ Of particular concern to this project, were the principles of informed consent, respect for rights of privacy and confidentiality, minimisation of risk of harm to the subjects, and limitation of deception. Informed consent and limitation of deception were assured by using a frank and explanatory cover letter accompanying the questionnaire. By returning the questionnaire, consent was implied. Given that the questionnaire was confidential rather than anonymous, the completed questionnaires were kept in a locked cabinet, to which only I had access. The documents will be destroyed within a year of the completion of the research. When the questionnaires were returned, the responses were entered into an Excel spreadsheet with a unique coding system. Each school's decile rating and its geographical area were added to the database entry but no identifying information was included. No names, addresses or identifying details of schools or principals are in any of the writing about the research and its findings.

This research is essentially inductive, in that it sought to build generalisations and theories from the themes that emerged during data analysis [see Figure 6]. It has not employed deductive logic, where there is a predetermined theory to be tested in the research, even though I assumed that there were significant numbers of children going hungry due to poverty. I was also aware anecdotally that some schools had policies and procedures to deal with hungry children, while other schools did not. Although these beliefs affected my decision to embark on the research project, they have not had an influence upon my analysis of the results.

\footnotetext{
${ }^{8}$ See Results chapter page 42 for information on the schools which returned the questionnaire.

${ }^{9}$ These principles are listed on page six of the VUW Human Ethics Committee Guidelines booklet, which can be downloaded from www.vuw.ac.nz/home/publications/hec_guidelines.pdf
} 
Figure 6: Inductive logic of this thesis (based on Creswell, 2003:132)

Data collection $\rightarrow \begin{gathered}\text { Data analysed into } \\ \text { themes/categories }\end{gathered} \rightarrow \begin{array}{cl}\text { Broad patterns and } \\ \text { generalisations } \\ \text { emerge from data }\end{array} \rightarrow \begin{aligned} & \text { Links made to } \\ & \text { past research/ } \\ & \text { theory }\end{aligned}$

A combination of descriptive and inferential statistics has been employed to analyse the quantitative data collected from the closed questions in the survey, to determine if there is a correlation between poverty and food insecurity. As noted earlier, the socio-economic indicator chosen for this research was the school decile rating. Decile ratings are calculated by the Ministry of Education, using the addresses of students supplied annually by every school. The socio-economic circumstances of households within the Census mesh-blocks pertaining to a school's students are used to determine the school's decile rating. The socio-economic indicators for each meshblock are: household income, occupation, household crowding, educational qualifications, and receipt of Income Support. The percentage of Maori and Pacific students in each school is also factored into the decile rating. Schools are ranked in relation to all schools in New Zealand for the six indicators mentioned, to arrive at an even number of schools in each decile rating. Decile 1 schools are the ten percent of schools with the highest proportion of students from low socio-economic communities, and Decile 10 schools are the ten percent of schools with the lowest proportion of these students. Although the school decile includes an ethnicity variable, which may skew the poverty variable, this is still the most accurate indicator available to measure the socio-economic status of primary school students.

I considered using an indicator of poverty which did not include an ethnicity element, such as the New Zealand Geographical Deprivation Index NZDep (Crampton et al., 2000). However, there would be no guarantee that the NZDep rating for the location of a school is the same as the NZDep rating of the students at the school; that is, students may not come from the immediate neighbourhood of their school. Given that this problem would be encountered with any socio-economic indicator, I decided to use the Ministry 
of Education's decile ratings - which have mitigated this problem already and acknowledge the limitations incurred by conflating ethnicity with other socio-economic measurements.

This research uses three indicators of food insecurity among children:

1. Children 'regularly hungry' throughout the school day

2. Children regularly coming to school without having eaten breakfast

3. Children regularly having no lunch or provision for lunch; that is, no food from home and no money to buy food

Primary school principals were asked to provide information on the children in their schools in Years 1 to 6 who they believed had these food insecurity indicators in the month of May 2004. As this research uses school principals' knowledge, the indicators are only 'estimates' of how many children are experiencing food insecurity. Some schools keep records of children who do not have breakfast and or lunch, but the majority of schools do not.

The open-ended questions from the returned questionnaire were entered into a Word document to allow for thematic analysis and have provided a valuable insight into the views of principals regarding the issue of children and food insecurity.

\section{An analysis of the questionnaire}

In general, the questionnaire used in this research proved to be very effective. Given the high response rate, and the lack of comments in relation to structure or wording issues, the questionnaire and its accompanying correspondence appear to have been easy to follow and quick to complete. As stated earlier, some low decile principals found it difficult to answer the first three questions which requested figures on the numbers of children experiencing food insecurity, and would have preferred to have kept a record for the following month rather than estimated retrospectively. However, this 
procedure would have required a significant amount of cooperation and time from principals and it is very possible that if that level of involvement was requested the participation rate would have been much lower. If the three questions regarding numbers of children experiencing food insecurity were placed later in the questionnaire some principals may not have been disconcerted by these problematic questions and would have filled in the bulk of the questionnaire before proceeding to these at the end.

If I were to repeat this research, the questionnaire would be modified in order to discover more about certain topics that I now perceive, in hindsight, are integral to the issue of food insecurity. Firstly, given that degradation in the quality of a child's food precedes a reduction in the quantity of a child's food on the food insecurity continuum [as discussed on page 4], it would have been useful to have more information regarding the quality of food children bring to school. Many principals did comment on this; however, it was effectively treated as a side-issue because I did not originally see its importance. Secondly, it would have been helpful if arrangements to respond to children experiencing food insecurity were more clearly delineated in the responses - i.e. organised as opposed to ad hoc arrangements - and if these had been dealt with separately in the questionnaire. In addition, it would have been useful to have divided questions regarding food into two questions about 'lunch' and 'breakfast' as many of the principals saw these two issues as separate. It would also have been of benefit to have requested more information from principals on the process behind the setting of policy and/or procedures in schools regarding their response to children experiencing food insecurity. However, this may well be a better topic for qualitative researchers to explore in future. In particular, this research could have benefited from information on how much debate occurs before the setting of policy regarding food insecurity, who are the key actors in the debate, and which organisations or professionals provide information, leadership or advice. It would also have been useful to elicit a response from principals specifically regarding the minimisation of stigmatisation for children involved in the provision of free food. In addition, it may have been advantageous to ask if their food programmes or policies were systematically 
evaluated, and if so, what the results of the evaluation were. However, given the small number of structured food programmes in the Wellington region, the responses are unlikely to have been insightful.

Any further research on food insecurity among children should consider using more detailed indicators to measure food insecurity among children than those which have been used in this research. Is asking principals to estimate the number of children whom they believe to be hungry, to have not had breakfast and who have no provision for lunch, the best way to quantify food insecurity among children? These indicators have provided a starting point to examine the issue and analyse the situation for Wellington primary school students, however, more research on indicators would be valuable. ${ }^{10}$

${ }^{10}$ See Conclusion page 69 for areas in need of further research regarding food insecurity among children. 


\section{RESULTS}

\section{Response rate to the questionnaire}

Principals in the Wellington region displayed strong support for this research. 188 questionnaires were posted and 115 were returned, giving a response rate of just over sixty percent. The responses are fairly representative of the schools in the region. Schools from all ten deciles were represented, with approximately fifty percent of schools in each decile range returning the questionnaire. Schools from every regional area in Wellington responded. However, only one-third of schools in Kapiti Coast and 38 percent of schools in South Wairarapa responded. Wellington City schools and Decile 9 and 10 schools are over-represented in both the actual population of schools in the region and in the proportion of questionnaires returned in this research [see Tables 1 and 2 in Appendix 5 for more detail].

\section{Food insecurity among children in the Wellington region}

Seven hundred and seventy children in the Wellington region were estimated by their principal to be 'regularly hungry' throughout the month of May. That was 3.3 percent of the total number of students in the schools that responded. Nearly 1500 children were estimated to regularly not have breakfast before school throughout the month of May. This figure represents 6.3 percent of the students in the schools that responded, making lack of breakfast the most common food insecurity indicator among children. And 437 children were estimated to regularly have no provision for lunch throughout the month of May: 2 percent of students in the schools that responded [see Tables 3, 4 and 5 in Appendix 5 for more detail]. 
The relationship between food insecurity and the socio-economic status of the students of a school, expressed in the decile rating, was very strong [see Figure 7]. Although there were hungry children in all deciles, children in low decile schools were much more likely to experience all of the food insecurity indicators. Two-thirds of children estimated to be regularly hungry were from Decile 1 to 4 schools, and nearly three quarters of children who regularly did not have lunch came from these schools.

Figure 7: Bar graph showing percentage of primary school students in each decile range estimated to experience food insecurity in May 2004.

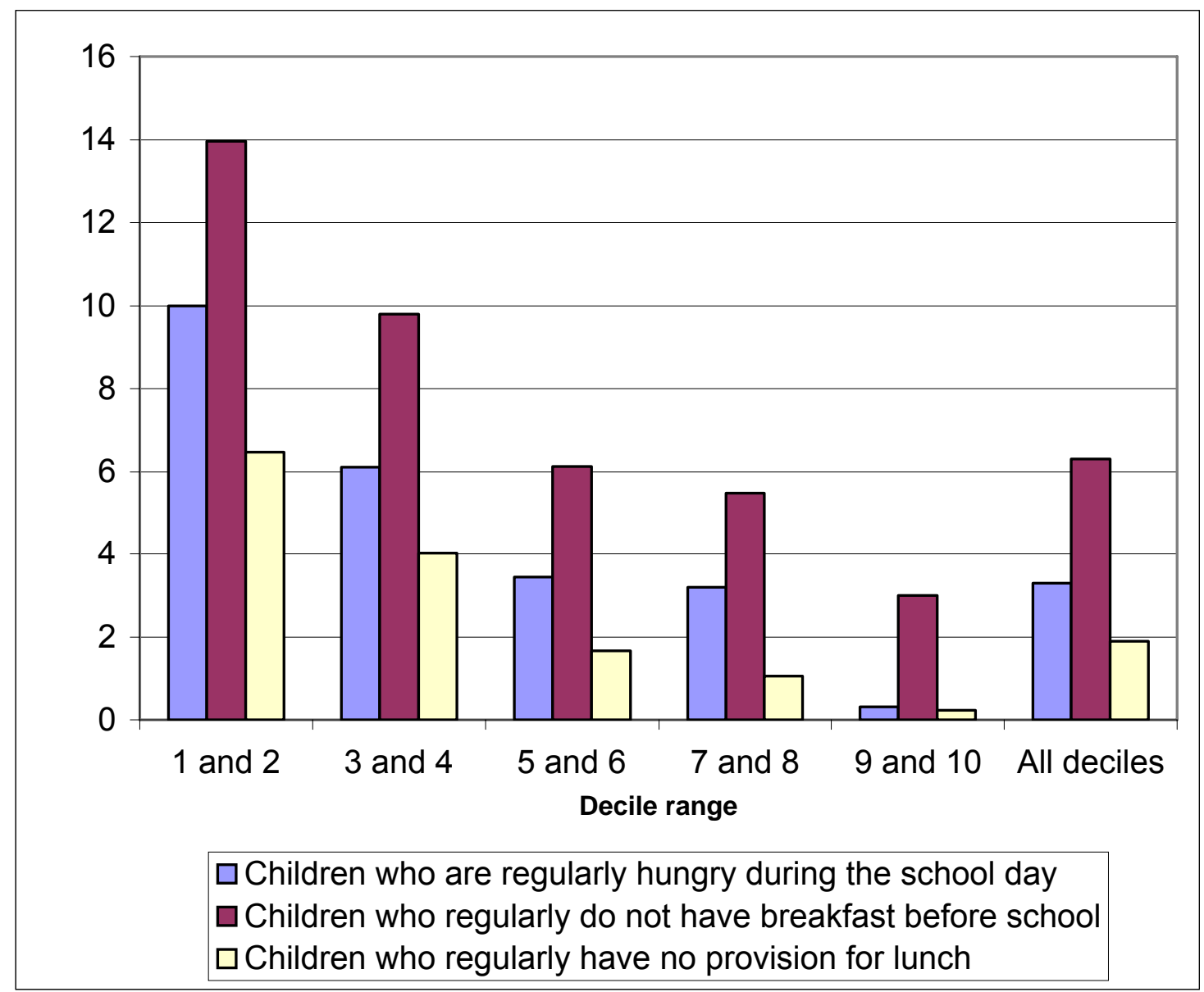

These percentages of hungry children (especially in Deciles 1 to 4 schools) must have real consequences for the day to day running of schools in the Wellington region. Consequently, this research sought to discover how schools respond to a child they believe is experiencing food insecurity. 


\section{School responses to food insecure children}

It appears that few schools in the Wellington region have systematically considered how they should respond to food insecurity issues. Nearly all Principals could explain what a teacher at the school would do if a child did not bring lunch to school. However, only a small number of schools had any policy or procedures beyond that immediate response.

\section{Written policy in schools regarding children and food}

Only twenty percent of principals stated that their school has written policy regarding children and food. The majority of schools with written policy were low decile (Decile 1 to 4 ) with nearly half of the schools with written policy coming from Decile 1 or 2 [see Tables 6 and 7 in Appendix 5 for more detail].

Eighty percent of written policy regarding children and food were 'Healthy Food' or 'Nutrition' policies, which generally include the two key concepts that healthy food options are available in the tuck shop/lunch-service and that children are taught about nutrition in the classroom. Some nutrition policies also included a clause that parents will be made aware of the policy and will be encouraged to provide healthy food choices for their children.

Only five of the 115 schools reported that they have written policy regarding the provision of free food to a child experiencing food insecurity; four of these policies are regarding when a child does not have lunch and one is for use when a child has not had breakfast. Four of these schools stated that they will contact the parents when lunch and/or breakfast are not provided on a regular basis, either by telephone or by letter. Two of the schools have a policy to notify the Department of Child, Youth and Family Services or a social worker if a child regularly has no food [see Appendix 6a for examples of written policy regarding children and food].

Two of the responding schools have very clear written procedures for teachers to follow when they have a student experiencing food insecurity. A Decile 9 school provided the template that the principal uses to send a letter 
to parents regarding food insecurity issues [see Appendix $6 \mathrm{~b}$ for this letter template]. One Decile 1 school made the statement in their policy that "№ child is to go without lunch" [emphasis in original] and attached a flow chart for teachers to use when they face a child who has no lunch, which includes the directive to send a letter home to parents when food is provided [see Appendix $6 \mathrm{c}$ for the flow-chart diagram]. The majority of schools, however, seemed to take a more informal approach.

\section{Informal procedures for when a child is facing food insecurity}

Ninety percent of school principals reported having informal procedures for teachers to follow when a student has not eaten breakfast and/or has no provision for lunch. All Decile 1 and 2 schools stated that they have such procedures [see Table 9 and 10 in Appendix 5 for more detail]. Informal responses of schools to food insecurity varied between schools, from organised free food programmes through to the ad hoc preparation of food when needed.

Seventy-five of the schools with procedures (65 percent of all schools) prepare food for a hungry child and a further twelve schools (10 percent) buy food from the local shop or lunch service for a hungry child. Nine principals mentioned that their school requests payment from the parents of the child to cover the cost of food provided (eight high decile schools and one Decile 6 school. Five principals reported that teachers share their food or provide money for food for a hungry child, and four said that other students are asked to share their food with any child without lunch. In twelve schools, teachers monitor children at lunchtime so that they can see who does not have lunch. Three schools would refer children to a social worker if there were ongoing concerns.

Organised food programmes in the Wellington region were rare. Only one school worked in collaboration with a community group to provide free food to children in need. Two schools ran a 'Breakfast Club' to which hungry children are referred (Decile 2 and Decile 4), and another mentioned they are investigating the possibility of starting a Breakfast Club (Decile 4). A Decile 2 
principal shared their system for providing free food to children who did not have lunch:

Normally we make sandwiches to sell at cost, that is 50 cents for two, and these go out daily with other tuck shop food. Parents are rostered to help. Those children who regularly have no lunch are on the list to receive sandwiches as part of the normal sandwich making system - i.e. no one knows they are receiving them for free.

One Kura Kaupapa Maori low decile school principal reported that students leave their packed lunch in the dining area before school and then at lunchtime the food is placed on communal dining tables for everyone to share. If a child does not bring lunch in the morning they would still have lunch with everyone else. Leftover sandwiches and fruit are rewrapped and given out after school. As a consequence of this procedure, the principal reported that they have no children 'regularly hungry' during the school day.

Many principals of schools that prepared food when required commented on the type of food they gave to hungry children. Most schools prepared sandwiches or toast, with a limited range of spreads available. Marmite and peanut butter were the most common spreads. Nine schools gave hungry children Weetbix or cereal and five gave fruit [see Table 10 in Appendix 5 for details]. A Decile 1 principal who fed five or six children a week at school commented:

Weetbix is cheap for us to supply and nutritious and filling for the child. It is also not exciting so children will prefer food from home. If we provide say pies for lunch they will leave their unappetising lunch at home on purpose so they can have a pie.

Three school principals (two Decile 3 and one Decile 7) stated that they thought minimising stigmatisation was very important when children have no lunch. One of these principals had "worked very hard to break down the stigmatisation, threat to pride, etc." so that parents or caregivers would contact the school to let them know that their child has no lunch and then the school could provide the child with food. Another commented: 
It is very important that children feel comfortable about accepting food. At our school we encourage children to come to the office or tell their teacher if they want food either morning tea or lunchtime or breakfast. At times we may have families that get all three 'meals' from us for a couple of weeks but then things usually come right. We occasionally have families ring to say 'please feed them'. (Decile 7)

Only one principal remarked that their school would punish a child who did not bring any food to school:

We have a rule at this school that helps promote sensible eating habits "No food, No play!" This ensures children have food for playtime and lunchtime. (Decile 5)

\section{How many schools provide free food?}

When asked how often free food is provided to hungry children, 74 principals stated that their school sometimes provided free food and 11 daily provided free food. In total, 74 percent of responding schools provided free food to hungry children. Of the 31 schools that did not provide food, thirty stated that this was because they did not have any hungry children at their school. Only one school, in Decile 6, said that they did not provide free food even though there were children in need at their school [see Table 11 in Appendix 5 for details].

The large majority of schools in Deciles 1 to 8 provided free food to hungry children either sometimes or daily. However, only forty percent of Decile 9 and 10 schools sometimes provided free food, and none of them reported the need to provide it daily [see Tables 12 and 13 in Appendix 5 for details].

Forty children in the region were reported to be given free food daily and a further 311 children were given free food sometimes; that was 1.5 percent of the children in responding schools that were given free food. However, those children were concentrated in Decile 1 to 4 schools, with Decile 1 and 2 schools providing free food to 5.5 percent of the total number of students in that decile range [see Table 14 in Appendix 5 for details]. 


\section{Who organises the provision of free food in schools?}

Due to the ad hoc nature of the provision of free food in schools, most of the organising was done by people 'on the spot' when a child was hungry. Nearly two-thirds of the time this was the child's teacher, and in many cases school office staff or the principal also organised free food for the child (or assist the teacher). Many principals responded to this question in the survey with multiple answers, for example, stating that the teacher and office staff organised free food [see Table 15 in Appendix 5].

There were only four schools in the region where parents helped directly with the provision of food. Two were Kura Kaupapa Maori schools where parents donated bags of fruit and had actively participated in the decision to do this, another was a Decile 9 school where the parents took turns to make cut sandwiches to be kept in the school freezer for hungry children, and the fourth was a Decile 1 school where the Board of Trustees organised the provision of sandwiches for children without lunch.

Only one principal in the Wellington region reported having the help of a community organisation to run a free food programme. This was a Decile 2 school that operated a 'Breakfast Club' once a week, which was organised in collaboration between staff and a community organisation. The other school in the Wellington region that had a breakfast club - a Decile 4 school which fed approximately ten children daily - was organised by the deputy principal with rostered teacher support.

\section{How do schools fund the provision of free food?}

Given that free food was supplied either sometimes or daily in the majority of schools in the Wellington region in May 2004, mostly without the assistance of community organisations, it is important to establish who paid for this free food. This research found that schools themselves usually funded the provision of free food to hungry children out of their school operations grant [see Figure 8 below]. This is the funding provided by the Ministry of Education for the running of a school. Fundraising leftovers (such as bread from sausage sizzles) or tuck-shop profits were used in over 10 percent of 
schools, and teachers or principals personally funded the provision of food for hungry children in a further 10 percent of all schools [see Table 16 in Appendix 5 for more detail].

Figure 8: Pie chart showing the source of funding for free food in schools.

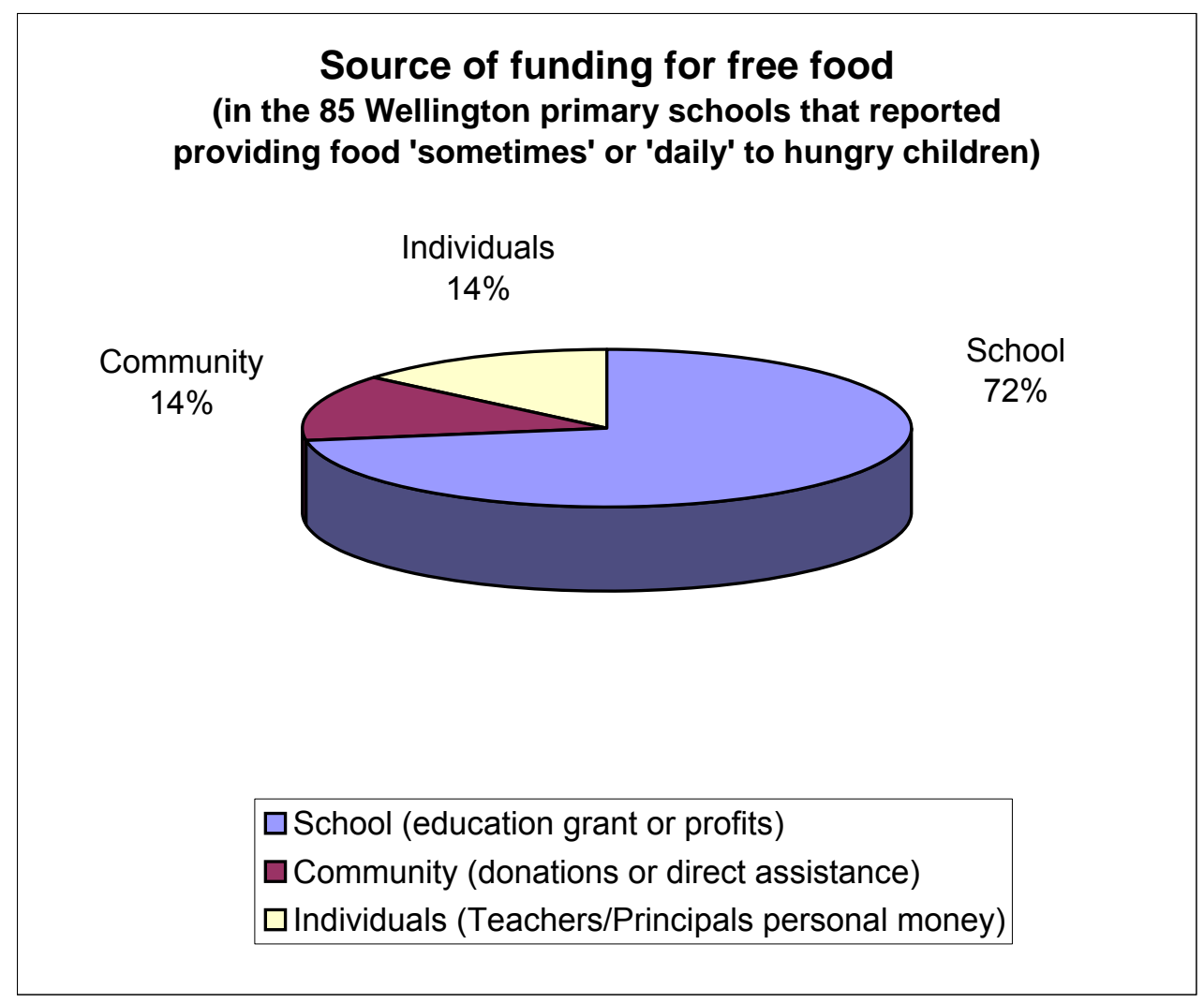

\section{Referrals to welfare professionals}

It is currently not mandatory for teachers or principals to report suspected cases of abuse or neglect of a child to welfare authorities (Child Youth and Family, 2001). However, ongoing or frequent instances where a particular child appears to have insufficient food should be referred to welfare professionals, such as a public health nurse or social worker. It appears that referrals have occurred in many schools in the Wellington region when there were food insecurity concerns.

Thirty-four schools in the Wellington region (30 percent of responding schools) had referred a child to either a public health nurse or a social worker in the past twelve months due to a concern about their food insecurity. Schools were most likely to refer children to a public health nurse, with the 
exception of Decile 1 and 2 schools who were more likely to refer children to a social worker. Ten schools ( 9 percent) had made referrals to both a public health nurse and a social worker in the past year. Three school principals that had referred children commented that food insecurity was only one of many concerns when a child was referred. Often there were also more general care and protection issues involved:

Lunches are one issue - then there is also, nits, dirty clothing, smelly shoes, runny noses etc. (Decile 2)

Twenty-two schools in the Wellington region (23 percent of responding schools) had referred children to a public health nurse (PHN) and 16 percent had referred children to a social worker in the past twelve months due to a concern about their food insecurity. Fourteen schools had referred more than two students to a PHN in the past year, with one of these schools (Decile 2) referring more than five students. Seven schools had referred more than two students to a social worker in the past year, with one Decile 4 school referring more than five students, and a Decile 1 school referring more than ten children to a social worker in the past year [see Tables 17-20 in Appendix 5 for details].

The majority of schools in the Wellington region did not refer any children to welfare professionals due to food insecurity issues over the past year, which would suggest that they did not see any evidence of food insecurity among their students. However, 30 percent of principals had estimated that a number of children at their school were 'regularly hungry' throughout the month of May and yet had not made any referrals to a welfare professional in the past year. Some of these schools had very high numbers of 'regularly hungry' children - there were eight schools with over fifteen hungry children during the month of May - and no referrals in the past year. One Decile 3 school recorded 45 hungry children in the month of May and had made no referrals in the past twelve months [see Table 21 in Appendix 5 for details]. It appears that a significant number of principals in the Wellington region did not report suspected cases of food insecurity among children to welfare professionals. 
A Decile 2 Principal commented that social workers should be attached to every school, remarking that it would be "wasting our time" to refer children to health professionals outside of the school because:

Parents keep children home rather than say they have no food once a public health nurse or a social worker is involved. They just ring and say their child is sick rather than be embarrassed.

Another Principal (Decile 6) stated that they would only refer a child to a welfare professional if:

...issues or trends indicate that a negative impact is being felt by our pupils. Otherwise we remain neutral.

This principal had referred two students with "questionable" diets to an RTLB (a special needs teacher) and a dietician, rather than a public health nurse or social worker.

\section{Principals' opinions on food insecurity among children}

This research aimed to not only determine the numbers of children affected by food insecurity and the responses of schools, but also to record the opinions of principals concerning several aspects of food insecurity among children. This section considers the opinions of principals on five issues: breakfast; lunch; the responsibility of parents and school to provide food to children; the link between absenteeism from school and food insecurity; and finally, whether schools should be a link to social services for children.

\section{Breakfast}

Over half of the responding principals agreed or strongly agreed with the statement that "Some parents find it difficult to provide breakfast for their child/ren every day" with less than one third disagreeing with this statement. These answers were strongly correlated with the decile rating of the school; 82 percent of Decile 1 and 2 principals agreed with the statement, whereas 
less than half of Decile 7 to 10 principals agreed [see Table 22 and 23 in Appendix 5 for more details].

The majority of principals' comments regarding breakfast were related to the difficulty parents face getting children to eat before school.

Some children refuse to eat breakfast - parents say it is available. (Decile 3)

A Decile 9 principal stated, "It is their own choice not to eat breakfast" while a Decile 7 principal added, "...for many at Year 5-6 level [9-10 year olds] breakfast is not 'cool'." Similarly, a Decile 10 principal commented:

Some children choose not to eat breakfast or lunch at this school, although food is available at home. It is not a poverty issue, it could be a peer pressure or image issue.

However, a Decile 2 principal believed parental neglect was more likely an issue:

Many of our students choose to skip breakfast because they are not supervised at home to ensure they bother to get some.

One Decile 4 school had banned eating at school before 9am to try to stop children eating their morning-tea "tasty snack food" before school and encourage the children to eat breakfast at home. A Decile 3 school principal commented that they would never provide breakfast at school because,

Often it is given or food is at home but children will not eat it. [emphasis in original]

One Decile 2 principal believed that their school had "a moral and ethical responsibility to see that the children can access food as a right" and, as mentioned earlier, this school organised a school breakfast once a week in partnership with a local community organisation, which sixty to eighty children attended. 


\section{Lunch}

Greater numbers of principals agreed with the statement that "Some parents find it difficult to provide lunch for their child/ren every day" than with the statement above regarding breakfast. Low decile school principals were more inclined to agree with the statement, with 88 percent of Decile 1 and 2 principals believing some parents had difficulty providing lunch for their child/ren, compared with less than half of principals from schools with Deciles 7 to 10 [see Table 24 and 25 in Appendix 5 for more details].

Principals across the decile ranges remarked that they were very concerned about the nutritional value of the school lunches provided to children:

Bought lunchpacks, large cookies, cheezles etc or 'power' drinks, a whole packet of biscuits, is considered by some as adequate food. (Decile 1)

We have a huge concern about the quality of food some children bring for lunch eg. chippies/cheezles and chocolate biscuits. We take fizzy drink off them if we see it and return it after school. (Decile 3, emphasis in original)

There is a definite trend of children from lower income families having bought lunches, pies, McDonalds, Fish and chips on some days and nothing on others. Very rarely do these children have the standard sandwich and piece of fruit and when this is offered will turn their noses up and have been seen discarding this lunch - they'd rather go hungry. (Decile 7)

Our food issues are more related to too much inappropriate and packaged food - sugar, food colouring etc. (Decile 9)

Some principals laid the blame for insubstantial or unhealthy lunches on the parents:

Parents make bad budgeting choices - fast, prepacked foods rather than home made sandwiches etc. Children are given dry noodles - very cheap for lunch or a whole packet of biscuits. (Decile 1)

The provision of lunch for children is a matter of prioritisation in the home. If parents prioritised spending, the money would be there. (Decile 10) 
While other principals thought that students were making the wrong food choices:

All our younger students bring excellent lunchboxes, but at about Year Four they are left to make their own lunch - they choose not to bother. (Decile 2)

The temptation to spend lunch money at the shop is often too great. Children's choices are not always healthy choices. (Decile 1)

A few principals thought that parents needed more information about healthy lunch options for children. One principal was especially concerned about refugees who may be unaccustomed to the culture of a packed lunch:

We now have a number of refugees who bring only biscuits. Help is needed on how to provide a cheap balanced meal. (Decile 2)

Some principals from low decile schools thought that there was a link between poverty and food insecurity:

Children are unable to learn when hungry - defeating one of the purposes of school. Poverty is rife in our community and many parents struggle to provide for their children. (Decile 1)

[There] ...seems to be less food available in households immediately prior to benefit/pay day. (Decile 1)

Several families have a lack of food before payday due to financial hardship. (Decile 2)

\section{Is it the school's responsibility to provide food?}

Principals in the Wellington region were in full agreement that it is the responsibility of parents to ensure that their children have lunch every day, with the majority of principals 'strongly agreeing' with this sentiment [see Tables 26 and 27 in Appendix 5]. However, some principals added a clause to this statement regarding the difficulty some parents face to provide adequate and appropriate food for their children, such as this Decile 5 principal: 
It is the parents' responsibility [to provide lunch] but with so many pressures on them sometimes they need a little help. No parent wants their child to be hungry.

Just over one third of principals thought that schools are also responsible for ensuring that every child has lunch every day, with a similar proportion of principals across the decile ranges agreed with this statement [see Tables 28 and 29 in Appendix 5].

Many low decile principals who thought that schools were not responsible for ensuring children were fed, added the comment that they would still give a hungry child food because hunger was detrimental to a child's ability to learn.

Whilst it is not the school's responsibility to provide lunch for children my personal philosophy is that children can't learn if they're hungry so it's in our interest to feed them. (Decile 3)

Our school chooses to be responsible for ensuring that every child has food every day for the good of the children's learning. (Decile 1)

It is not the school's role to ensure children have lunch every day. However we are not going to let children go hungry. It affects their learning. (Decile 1)

We agree that children need food to make the most of learning opportunities; therefore, we see it as a moral and ethical responsibility to see that the children can access food as a right. (Decile 2)

A couple of low decile principals stated that due to the 'pastoral care' role of schools, they had a duty to feed hungry children:

Whilst it is not the responsibility of a school to feed students, it should come under the umbrella of pastoral care and concern to ensure that children are fed. (Decile 1)

Schools are not responsible for providing lunches however we have a duty of care to make sure no child goes hungry. If the child lets the teacher or other staff know, we will always provide food. (Decile 1) 
Forty-two principals (37 percent) believed that it is both the parents and the schools' responsibility to ensure every child has food every day. One Decile 8 principal commented:

Ensuring children have food should be a partnership between school and parents.

\section{The link between absenteeism from school and food insecurity}

Principals were strongly divided on the link between absenteeism and food insecurity issues. Eighty-eight percent of Decile 1 and 2 principals agreed that children experiencing food insecurity sometimes miss school, in contrast with the fourteen percent of Decile 9 and 10 principals who agreed with this statement [see Figure 9 below]. Many high decile principals noted that they had answered this question with respect to their school population, not the general student population.

Figure 9: Bar graph showing the opinions of Principals on the link between food insecurity and absenteeism from school by decile rating

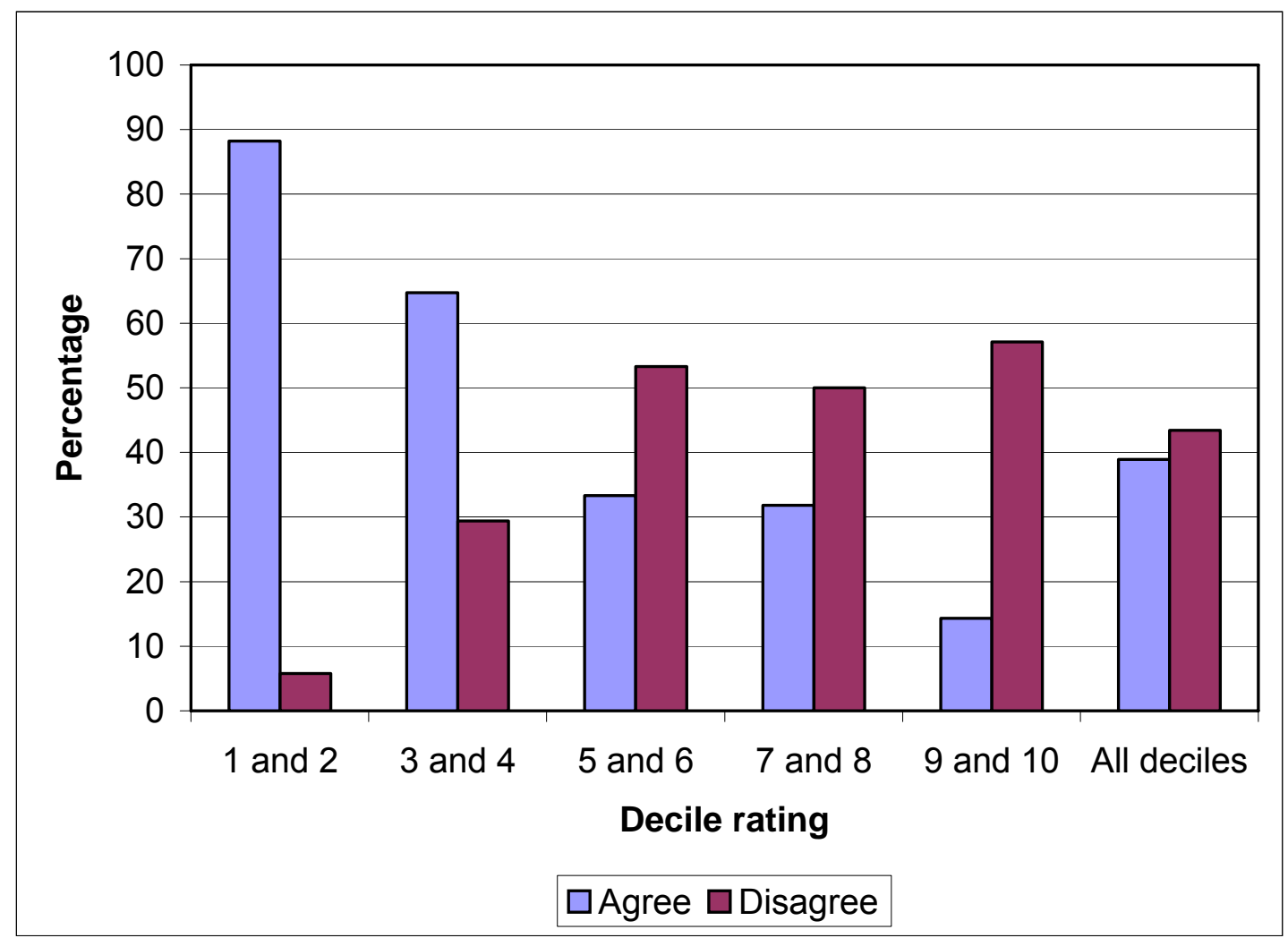

Note: 'Don't know' answers and no response excluded from the graph. Refer to Tables 30 and 31 in Appendix 5 for complete results. 
Two Decile 1 school principals explained why they believed there was a link between food insecurity and absenteeism from school. Both mentioned embarrassment of the parents rather than the child, and the parents' fear of being reported to welfare professionals or being labelled "a bad parent".

One principal commented that their school had tried to ensure that absenteeism would not be an issue for their students:

Parents would sometimes comment that 'absenteeism' was a result of their child not having lunch, but we would tell them it was better for them to come to school and have a lunch provided for them than being home hungry - so this statement is correct but does not apply at our school anymore. (Decile 5)

\section{Schools as a link to social services for children}

Ninety-five percent of principals in the Wellington region agreed that schools are an important link in the provision of social services for children. However, ten percent of principals in Decile 9 and 10 schools disagreed [see Tables 31 and 32 in Appendix 5 for more information]. The following two quotes are representative of the principals from high decile schools who disagreed that schools are an important link between children and social services:

Schools are educational establishments and they do have a role to play in reporting incidents where children are consistently hungry but not in resolving the issue. This is a social welfare not a school issue. I feel strongly that all too often teachers are expected to fulfil roles that should be being carried out by parents and other agencies. Fulfilling these roles takes too much time away from the task they were employed to do: teaching. (Decile 10)

Social services and food for children has become school's issue, but there should be other agencies working with families to ensure children do not have these needs. Schools are picking up issues and problems that it should really not have to. (Decile 10)

Other principals who agreed that schools were an important link to social services for children also voiced their opinion that the welfare of children should not be their primary concern as they were essentially educators: 
School's primary role is to provide quality teaching and learning programmes - not be social welfare institutions - teachers need to focus on teaching not be social workers... Parents have the care and protection responsibility - parenting skills or lack of them is our greatest concern. (Decile 4)

I agree that we are important [as a link to social services] because we notice when things aren't right for a child - but I don't think we should be because we are busy doing a lot of other things to do with educating children. (Decile 7, emphasis in original)

Schools have become a link for provision of school services whether they like it or not. Schools should be able to focus on core business of education but social circumstances force them to take a wider view. (Decile 9) 


\section{DISCUSSION}

This chapter considers the results of the Children, Food and Poverty research in light of previous research on food insecurity among children in New Zealand from the FNCS survey in 1995 and the National Children's Nutrition Survey in 2003. Direct comparisons between these pieces of research cannot be made due to the differing populations and questions in the research. However, in accordance with critical realism, ${ }^{11}$ research findings are seen as "evidentiary tools", rather than exact evidence. As such, a joint analysis of the three studies can still give us some insight into the reality of food insecurity for children in Wellington schools. Comparisons highlight the fact that food insecurity remains an important issue for schools.

The responses from primary school principals in the Wellington region demonstrate that food insecurity is prevalent among children, and that the responses of schools to this issue are in most cases inadequate. I will argue that responses to food insecurity are generally ill-considered due to a lack of understanding and discussion of the issue, which has in turn lead to poor policy and procedure development. This is not necessarily the fault of primary school principals or the school communities, but instead it is the result of a culture where targeted charity for "the deserving poor" prevails, rather than the principle of social justice for everyone.

\section{Food insecurity among children in the Wellington region}

Some primary schools in the Wellington region currently have to contend with a number of children who routinely arrive at school without having had breakfast, who do not have any provision for lunch and who, as a consequence, are hungry throughout the school day. Other children at school may experience only one or two of these indicators of food insecurity.

\footnotetext{
${ }^{11}$ See Methodology chapter page 30 for information on critical realism.
} 
This research has confirmed the anecdotal stories of hungry children in schools and has given a clear indication of which schools are most likely to be affected.

As shown in the results of this study, there are children experiencing food insecurity in schools from all of the Deciles 1 to 10 . However, Decile 9 and 10 schools (schools in the wealthiest 20 percent of communities) are considerably less affected by this issue than schools in the other eight deciles. This result is consistent with the ELSI research, ${ }^{12}$ which has found that there is significant inequality, demonstrated in the gap in living standards, between the wealthy and the poor in New Zealand society.

Clearly visible in the results of this research is the disproportionate burden on schools which service the poorest twenty percent of communities in New Zealand; Decile 1 and 2 schools. These schools on average reported having ten percent of their students regularly hungry during the school day throughout the month of May.

The strong relationship between poverty - as measured by the school decile system - and food insecurity among children confirms that, in regards to food insecurity at least, the decile ratings of schools are a clear predictor of need. This is an interesting finding, as the school decile rating system has been strongly criticised as a 'race-based' policy that is ineffectual in measuring genuine need. As a consequence of this criticism, the school decile rating system has changed and as of January 2005 it does not include an ethnicity variable (Mallard, 2004). Schools with a high proportion of Maori or Pacific students may no longer be eligible for a low decile rating and they could lose some of their extra funding. Yet the results of this research suggest that the previous allocation of deciles, which included an ethnicity variable, was accurately aligned with the needs of children. This is consistent with the findings of the Children's Nutrition Survey (Ministry of Health, 2003b) which found that non-Pakeha families were more likely to be food insecure.

\footnotetext{
${ }^{12}$ As outlined on page 12 of the Literature review.
} 
Another important finding from this research is the clear relationship that principals of schools in Deciles 1 to 4 believe exists between food insecurity among children and absenteeism from school. Stories in the media about children being kept at home because they have no food to take to school were common during the 1990s and Reid's thesis documents some of these stories. ${ }^{13}$ This research has found that principals believe the practice still occurs, and that they attribute the link between food insecurity and absenteeism to parents feeling shame, embarrassment or fear. The statements from principals on this issue concur with the findings of Raine, McIntyre and Dayle (2003) that parents rather than children are most worried about stigmatisation.

It is apparent that the issue of food insecurity among children has not disappeared over the past ten years. Principals continue to be concerned with food insecurity, as indicated by the large number of principals who added their comments and opinions to the completed questionnaires, and many children still receive free food at school. When comparing the Children, Food and Poverty results with the FNCS research on food insecurity among children throughout New Zealand in 1995, it appears that the Wellington region has fewer numbers of children affected by food insecurity than the rest of the country had ten years ago. There are approximately one third less children in the Wellington region in May 2004 who did not have breakfast and who did not have lunch, than in the FNCS research. However, the same proportions of children were estimated to be regularly hungry throughout the school day in both studies, that is, just over three percent of children.

The results from this research are consistent with the Ministry of Health's National Children's Nutrition Survey findings, which report that a small number of children from NZDep01-V households (the bottom twenty percent of households in New Zealand) are suffering from food insecurity, with 2.5 percent not having any food during school hours over the period of a week. Principals from Decile 1 and 2 schools in this research estimated that just

\footnotetext{
${ }^{13}$ See page 22 in the Literature review.
} 
over six percent of their students regularly had no lunch over a one-month period. The differing proportion of children affected in these two pieces of research suggests that some of the children who regularly had no lunch in May 2004, did have lunch on some days during the week but they did not have lunch 'regularly' over the whole month of May 2004. This scenario is probable, and supported by the Poverty Measurement Project's research with low income families ${ }^{14}$ which showed that poor households often work to a weekly budget, and that when food runs out the household waits until the next payday to buy more. Two principals from this research concurred that some families struggle to provide food immediately prior to pay day.

This research also asked principals to record the number of students they had referred to welfare professionals in the past year due to a concern for their food security. Thirty percent of schools had referred at least one student experiencing food insecurity to a Public Health Nurse or a Social Worker within the past year. As this is the same proportion of schools in the FNCS research in 1995, we can infer that the food insecurity situation for children has not improved over the past decade. Given the seeming reluctance for principals to refer children to welfare professionals, as indicated in comments on page 51, the substantial number of schools referring children is confirmation that the level of food insecurity in these cases may be quite severe. The children referred to welfare professionals are likely to represent a small proportion of children experiencing food insecurity if we take into consideration the food insecurity continuum.

The percentages of children reported in this research to be experiencing food insecurity may seem small, but the absolute numbers are worth remembering; 770 children in the Wellington region were estimated to be regularly hungry throughout the month of May, nearly 1500 regularly did not have breakfast, and 437 regularly did not have lunch during that month. Although it is impossible to determine from this research if the number of children affected by food insecurity has increased over the past ten years, it is apparent that food insecurity and hunger are a reality for a number of New

\footnotetext{
${ }^{14}$ See page 18 in Literature review.
} 
Zealand children, and that consequently this continues to be an issue for schools.

\section{The provision of free food to hungry children}

Ten years ago the FNCS research found that just over half of all Wellington schools provided free or subsidised food to students. This compares with 74 percent of primary schools in the Wellington region today that provide free food. This research has found that nearly all Decile 1 to 6 schools in the Wellington region provide free food sometimes or daily to a small number of hungry children, and that many schools in Decile 7 and 8 also do this. In general, only principals of Decile 9 and 10 schools believe that there is no need for them to ever provide free food.

The number of children in primary schools that receive free food are relatively small; 40 children receive free food daily in 11 schools, and a further 311 children in 74 schools receive food sometimes. When compared to the 437 children who regularly did not have lunch and the 770 children who were estimated to be regularly hungry during the school day throughout the month of May 2004, it appears that only a minority of children experiencing food insecurity are given free food. Although most schools are providing free food to hungry children sometimes, this response is clearly not matching the scale of the problem.

Lack of funding for the provision of free food to hungry children is one possible reason why some schools are not feeding children that they know to be in need. There is very little community organisation involvement in the provision of food in Wellington schools, and furthermore, few schools receive monetary donations or gifts of food. This was also the situation ten years ago, when the FNCS research found that only 15 percent of New Zealand primary schools received help from the community, financial or otherwise, to deal with the issue of hungry children. For the 70 schools in the Wellington region that do not receive community assistance to provide free food for 
hungry children, the money either comes out of the school's operations budget or teachers' pockets. Some principals commented that it was not a huge expense. However, the fact that schools are funding the provision of free food raises the issue of responsibility: are schools responsible for every aspect of the welfare of children in their care? Two-thirds of principals from Decile 1 to 6 schools thought that their school was not responsible for ensuring that every child has lunch everyday, yet many of them effectively assume that responsibility by providing food to children in need.

\section{School policy and procedures for responding to food insecure children}

This research has found that very few schools have written policy regarding how to respond to food insecurity. This lack of written policy can be attributed to the fact that schools struggle to determine the boundaries of what falls within their responsibility. The issue of food security among children encompasses the diverse policy areas of health, welfare and education. In 1936, Boyd Orr concluded his research on food and poverty in England by stating "one of the main difficulties in dealing with these problems is that they are not within the sphere of any single Department of State" (Boyd Orr, 1936). New Zealand has this very problem today, with the principals involved in this research indicating uncertainty about the role of schools in responding to food insecurity. Ninety-five percent of principals believed schools were an important link in the provision of social services to children, however this did not equate with an acceptance of responsibility for anything other than children's educational needs. The number of principals who believed schools were responsible for ensuring their students did not go hungry fell to just over one in three, and only a couple of principals acknowledged 'pastoral care' as a role of schools. The Ministry of Health believes schools are a central "supportive environment" for a coordinated response to food insecurity in New Zealand, yet many of the principals in this research have indicated that schools do not have the required knowledge, resources and the motivation to assume this role. 
While they may lack written policy, nearly all schools in the Wellington region have informal procedures for their teachers to follow when a child is hungry which is confirmation that schools are responding to the issue of food insecurity in a compassionate manner. However, informal procedures can be problematic as a response to food insecure children, in that they are subject to the understanding of the individual teacher confronted with a hungry child. As such, they have the potential to result in ill-planned, ad-hoc arrangements which can stigmatise the child. Unfortunately, this appears to be the case in several of the schools in the Wellington region. Instances of teachers or other students having to share their food with a child who does not have lunch, and of schools requiring a child to ask a teacher for food in front of classmates, may possibly result in a loss of dignity and the stigmatisation of the food insecure child and their family.

A small number of schools in the Wellington region have given detailed consideration to the issue of food insecurity. These schools have formulated procedures in a structured manner, usually with community input, and as a result have the best systems in place to minimise stigmatisation of food insecure children and their families. A good example of this considered response is the Kura Kaupapa Maori school that communally shares food at lunchtime. Parents were actively involved in both the policy development and the practical application of this food policy. Another example of a planned response to food insecurity is the Decile 2 school that operates a breakfast club in collaboration with a community organisation. In addition, the school that places children with a perceived food security problem on a list to receive free food at lunchtime with anonymity is a further example of how schools can safe-guard the interests of the child.

Only one example in this research does not support the assertion that the more a school considers its response to food insecurity, the better its policy and procedure will be, and that is the Decile 5 school which punishes children by not allowing them to play if they do not bring food to school. This practice demonstrates a common misunderstanding of the issue of food 
insecurity - that it is the fault of the individual - and is evidence that more education of teachers and principals is required.

There is clearly reluctance within schools to form written policy on the issue of food insecurity; with the resounding comment from principals that hungry children are not their problem. This is an understandable position; schools are primarily educational institutions that do not receive funding from the Ministry of Education to deal with this issue. Nevertheless, nearly threequarters of schools in the Wellington region are currently providing free food to hungry children, funded in most cases by the schools themselves. These schools are responding in a charitable manner, showing compassion for children in need. They do not - and cannot be expected to - take responsibility for solving the problem of food insecurity among children.

Schools that provide free food undoubtedly have the interests of the child as their paramount concern, and they are alleviating the immediate concern of hunger. However, while food continues to be provided in a charitable ad-hoc manner in schools, society has failed to address the underlying cause of hunger among children in New Zealand.

...the right to food is not a right to "free" or unconditional food... the right to food does not generate an obligation for every individual to provide direct food assistance to those who would otherwise be hungry. Individual donations to food kitchens or food banks out of a humanitarian or charitable duty alleviate hunger, but they will not suffice to solve the problem...

(Li, 1996:166) 


\section{CONCLUSION}

\section{The significance of this research}

The Children, Food and Poverty study has confirmed that there is a small number of hungry children in most Wellington primary schools and that the responses to these children are generally inadequate due to an insufficient understanding of the issue of food insecurity. Most significantly, this research has confirmed the strong correlation between poverty (as measured by the school decile rating) and food insecurity among children in the Wellington region. The findings of this research are succinctly conveyed in this comment from a Decile 1 principal:

Children are unable to learn when hungry - defeating one of the purposes of school. Poverty is rife in our community and many parents struggle to provide for their children.

Hungry children in schools are symptomatic of the final stages in the food insecurity continuum, and are therefore evidence of a wider problem in our society. In order to be successful, any response to this manifestation of food insecurity must address earlier steps on the continuum and the fundamental causes of food insecurity. This thesis asserts that it is crucial for schools and our society at large to understand and apply a social justice framework, as opposed to a 'charity' approach, in our responses to food insecurity. A charity approach - for example, giving selected children free food without regard to the consequences of stigmatisation for them and their family creates a loss of human dignity and is not solving the underlying problem. In contrast, social justice is about securing basic welfare rights for everyone; individuals are entitled to a basic standard of living and, as a consequence, no-one need feel shame about their situation. As Dowler (2002:710) states:

A rights framework introduces accountability, and implies a normative basis to responses rather than that of a safety-net or emergency. 


\section{Limitations of this thesis and areas for further research}

This research could be improved and expanded in the future in several areas, in addition to modifications to the questionnaire as discussed earlier. ${ }^{15}$

Food insecurity among children, and people in Western countries generally, is an under-researched area and there is certainly a need for more work on this issue. Due to resource constraints, the Children, Food and Poverty research has been limited to primary schools in the Wellington region and was only able to use the 'estimations' of principals. Further research which attempts to more accurately discover the numbers of children throughout New Zealand facing food insecurity would be valuable. More evidence of this problem and its effects is essential in order to move to the next stage of analysing the underlying causes and formulating solutions.

In the absence of any large-scale collection of data, this research has provided a model for a questionnaire that can be adapted by local communities, health professionals and schools for their own use in researching food insecurity in their community. Many schools already undertake informal surveys of how many children have not had breakfast or lunch, however care must be taken to avoid stigmatisation during this procedure. Teachers inconspicuously recording the children in their class without food would be preferable - and most likely more accurate - to a public 'showing of hands' from children. Research which could investigate the reasons why individual children arrive at school without having eaten breakfast and/or with no provision for lunch would also be insightful.

The greatest limitation of the Children, Food and Poverty research is that it has relied largely on quantitative data collected by a single postal questionnaire. Although this method was adequate for the purposes of answering the research questions, the data cannot adequately address many of the complex issues which have inductively arisen as important considerations. There are three areas in particular where qualitative

\footnotetext{
${ }^{15}$ See page 40 in the Methodology chapter.
} 
interviews or case-study approaches would be beneficial and where further research in this area is needed:

- An exploration of the different applications of 'social justice' and 'charity' approaches to food insecurity among children in schools

- The experiences and attitudes of social workers and public health nurses in regard to food insecurity among children

- A study of the incidence and effects of stigmatisation for children and their families when they are involved in free food programmes.

Any future research on food insecurity among children should be informed by an understanding of the food insecurity continuum, ${ }^{16}$ meaning that it should concentrate not only on the quantity of food consumed but also the quality of food. It would be beneficial if research was undertaken to clarify the link between food insecurity, poverty and obesity in children. Are children from low socio-economic families more likely to be obese than children from wealthy families? Is obesity in children a sign of food insecurity? Is this a problem of parental education or is there a lack of economic resources within the family to buy healthy food? This research has not adequately addressed the issue of the quality of food being consumed by children at school and there is a pressing need for research which can assess whether poverty is linked to food quality, in the same way that it is linked to the quantity of food consumed.

\section{Possible strategies and policy implications}

The world produces enough food to feed every man, woman and child on earth. Hunger and malnutrition therefore are not due to lack of food alone, but are also the consequences of poverty, inequality and misplaced priorities.

UNICEF Deputy Executive Director, Kul C. Gautam World Food Summit: Five Years Later, November 2002

\footnotetext{
${ }^{16}$ See Figure 1 on page 3 of the Introduction.
} 
The application of a social justice approach to the issue of food insecurity among children would result in significant policy changes at school, community and government level in New Zealand.

This research points to the need for schools to create comprehensive policy regarding children and food. Only Decile 9 and 10 schools in the Wellington region do not appear to require a specific policy on this issue. Any written policy should confirm food as a right and recognise the food insecurity continuum. It should provide an avenue for the provision of free food to children in need, without punishment or stigmatisation of the child or parents, and should outline clear procedures for the referral of children to welfare professionals when necessary. Ideally, those with an understanding of food insecurity - such as welfare professionals, the Ministry of Health, or the Ministry of Education - would be involved in the writing of this policy.

This research has found that principals (with the exception of some principals of Decile 9 and 10 schools) affirm the role of schools as an important link to the provision of social services for children, as long as it does not hinder their primary role as educators. The extension of the Social Workers In Schools (SWIS) programme and an increase in the numbers of public health nurses would be beneficial in reducing food insecurity among children. These welfare professionals could bridge the gap between the Ministry of Health and schools, and assist in educating teachers and Board of Trustees about food insecurity. They could also ensure that schools are responding to food insecure children appropriately and could help to facilitate community involvement in the issue.

At the community level, it is clear that more debate on this issue is needed. The myths regarding hunger in developed countries are widely believed, and a greater understanding of the causes of food insecurity is needed. Some communities in New Zealand, such as in Manukau City, have accepted responsibility for the problem of food insecurity among children in schools and have consequently started free food programmes for children in need. This thesis does not advocate this solution for all communities, and stresses 
that the provision of free food should be for all children in a school rather than targeted to 'those in need' if it is to be effective and avoid stigmatisation. As discussed in the background section of the thesis, free food programmes can be detrimental to the self-esteem and dignity of children and their families, and often free food does not reach the children in most need. However, local initiatives - such as a community group donating boxes of fruit to be distributed to all children in a school at morning tea time - are to be applauded and recommended. For community groups looking to be involved in free food programmes, Dowler (2002:711) observes:

Local and community-based initiatives have an important role as part of a range of solutions to food and poverty, but the increasing amount of research evaluating their effectiveness and sustainability, shows how critically both depend on sustained rather than start-up funding, shared ownership between communities and professionals, and realistic, flexible timeframes and goals.

Given that this research has found a strong connection between food insecurity among children and poverty, solutions to the issue of food insecurity need to focus on reducing the number of children living in poverty in New Zealand. The responsibility for this lies with the government. The current government is clearly concerned with the issue of child poverty - the reduction of child poverty was mentioned by Prime Minister Helen Clark in the 2004 Budget Speech - yet there has been no time-frame given for the elimination of child poverty in New Zealand. When we have nearly one-third of children living in households below the poverty line, urgent attention needs to be given to combating child poverty.

It is often claimed that the welfare system provides more than enough money for people to survive, yet there is no relationship between set benefit levels and the amount of money required for an acceptable standard of living in New Zealand. More political consideration is given to the preservation of an adequate gap between the minimum wage and benefit levels, in order to maintain an incentive for beneficiaries to work, than to the preservation of an adequate standard of living among the poor in New Zealand. If New Zealand is to take seriously the commitments it has made internationally to maintain 
the right to food for all citizens, the eradication of child poverty must be prioritised by ensuring that all families have an adequate income to address their food needs.

If the problem of hunger in wealthy and technologically advanced countries is to be eliminated it must first be recognised that hunger is essentially a political question and a fundamental issue of human rights and distributive justice (Riches, 1997:174). 


\section{References}

Alaimo, K., Olson, C., \& Frongillo, E. (2001). Food insufficiency and American school-aged children's cognitive, academic and psychosocial development. Pediatrics, 108 (July), 44.

Archer, M. (1995). Realist Social Theory: the morphogenetic approach. Cambridge: Cambridge University Press.

Barker, R., \& Currie, A. (1994). Food Security in Christchurch. Paper presented at NZDA Conference. Christchurch: Public Health Service, Healthlink South.

Blaiklock, A., Kiro, C., \& et. al. (2002). When the Invisible Hand Rocks the Cradle: New Zealand children in a time of change. Florence: UNICEF Innocenti Research Centre.

Boston, J., Dalziel, P., \& St. John, S. (1999). Redesigning the Welfare State in New Zealand: problems, policies, prospects. Auckland: Oxford University Press.

Boyd Orr, J. (1936). Food, Health and Income: Report on a survey of adequacy of diet in relation to income. London: Macmillan.

Brooks-Gunn, J., \& Duncan, G. (1997). The Effects of Poverty on Children. The Future of Children, 7 (2 Summer/Fall), 55-71.

Centre on Hunger Poverty and Nutrition Policy. (1995). Statement on the Link between Nutrition and Cognitive Development in Children. Massachusetts: Tufts University School of Nutrition.

Child Poverty Action Group. (2003). Our Children: the priority for policy (2nd ed.). Auckland: CPAG.

Child Youth and Family. (2001). Let's Stop Child Abuse Together: An interagency guide to breaking the cycle. 2nd ed. Wellington: Department of Child, Youth and Family Services.

Clark, H. (2004). Budget Speech. Available from www.beehive.govt.nz.

Coalition of Wellington Region Food Banks. (1996). Food Banks in the Greater Wellington Region. Wellington: Caritas Aotearoa New Zealand. 
Crampton, P., Salmond, C., Kirkpatrick, R., Scarborough, R., \& Skelly, C. (2000). Degrees of Deprivation in New Zealand: An altlas of scoioeconomic difference. Auckland: David Bateman Ltd.

Creswell, J. W. (2003). Research Design: quantitative, qualitative and mixed methods approaches (2nd ed.). Thousand Oaks: Sage.

Crotty, M. (1998). The Foundations of Social Research: meaning and perspective in the research process. Crows Nest, NSW: Allen \& Unwin.

Cruickshank, J. (2003). Realism and Sociology: anti-foundationalism, ontology and social research. London: Routledge.

Department of Human Nutrition. (2004). Food Cost Survey Data, August 2004. Dunedin: University of Otago. Available from http://nutrition.otago.ac.nz.

Dillman, D. (2000). Mail and Internet Surveys: the tailored design method. New York: John Wiley \& Sons.

Dowler, E. (2002). Food and Poverty in Britain: Rights and Responsibilities. Social Policy and Administration, 36 (6), 698-717.

Dreze, J., \& Sen, A. (1995). The Political Economy of Hunger. Oxford: Claredon Press.

FAO. (2000). The State of Food Insecurity in the World 2000. New York: Food and Agricultural Organisation of the United Nations. Available from www.fao.org.

Farrell, M. (2003). Help needed to feed hungry children. Auckland Stuff: INL Newspapers. Available from www.aucklandstuff.co.nz.

Food and Nutrition Consultancy Service. (1995). Final Report of the Public Health Commission on the perceived food inadequacy among children in schools. Dunedin: University of Otago.

Fowler, A., \& Schmidt, J. (1994). Hungry Mouths. Metro, June, 72-82.

Human Rights Commission. (2004). Human Rights in New Zealand Today. Wellington. Available from http://www.hrc.co.nz.

Inland Revenue Department. (2004). Example of the increases and changes to family assistance: Scenario 4. Available from www.ird.govt.nz/promotion/wff/examples.html. 
Krishnan, V., Jensen, J., \& Ballantyne, S. (2002). New Zealand Living Standards 2000. Wellington: Centre for Social Research and Evaluation, Ministry of Social Development.

Leather, S. (1997). Food Poverty: the making of modern malnutrition. Health Visitor, 70, 21-24.

Li, X. (1996). Making Sense of the Right to Food. In W. Aiken \& H. LaFollette (Eds.), World Hunger and Morality (2nd ed.). New Jersey: Prentice Hall.

Lopez, J., \& Potter, G. (2001). After Postmodernism: the millennium. In J. Lopez \& G. Potter (Eds.), After Postmodernism: An Introduction to Critical Realism (pp. 1-18). London: The Athlone Press.

Lucas, P. (2003). Breakfast clubs and school fruit schemes: Promising practice. London: The Evidence Network. What Works for Children Group - Evidence Nuggets. Available from www.whatworksforchildren.org.uk.

Mallard, T. (2004). First results of review of targeted programmes. Wellington: Available from www.beehive.govt.nz.

McMahon, W., \& Marsh, T. (1999). Filling the Gap: Free school meals, nutrition and poverty. London: Child Poverty Action Group UK.

Ministry of Health. (1999). NZ Food NZ People: Key results of the 1997 National Nutrition Survey. Wellington: Ministry of Health.

Ministry of Health. (2003a). Healthy Eating - Healthy Action: Oranga Kai Oranga Pumau A Background. Wellington: Ministry of Health.

Ministry of Health. (2003b). Healthy Eating - Healthy Action: Oranga Kai Oranga Pumau A Strategic Framework. Wellington: Ministry of Health.

Ministry of Health. (2003c). NZ Food NZ Children: Key results of the 2002 National Children's Nutrition Survey. Wellington: Ministry of Health.

Ministry of Health. (2004). Healthy Eating - Healthy Action: Oranga Kai Oranga Pumau Implementation Plan 2004-2010. Wellington: Ministry of Health.

Ministry of Health. (2004 revised ed.). Eating for Healthy Children Aged 2-12. Wellington: Ministry of Health. Available from www.moh.govt.nz.

Ministry of Social Development. (2002). New Zealand's Agenda for Children. Wellington: Ministry of Social Development. 
Ministry of Social Development. (2004a). The Social Report. Wellington. Available from www.socialreport.msd.govt.nz.

Ministry of Social Development. (2004b). The Statistical Report. Wellington. Available from http://www.msd.govt.nz/work-areas/socialresearch/statistical-report.html.

Nelson, M. (2000). Childhood nutrition and poverty. Proceedings of the Nutrition Society, 59, 307-315.

New Zealand Network Against Food Poverty. (1999). Hidden Hunger - food and low income in New Zealand. Wellington: Downtown Community Ministry.

NZ Milk Board. (1966). Milk in Schools Scheme: A review. Wellington: New Zealand Milk Board.

NZCCSS. (2004). Poverty Indicator Project: Foodbank Study Summary Report. Wellington: New Zealand Council of Christian Social Services.

Parnell, W. (1997). Socioeconomic disadvantage and nutritional status in New Zealand. In B. M. Kohler, E. Feictinger, E. Barlosius \& E. Dowler (Eds.), Poverty and Food in Welfare Societies. Berlin: Sigma.

Parnell, W., Reid, J., Wilson, N., McKenzie, J., \& Russell, D. (2001). Food Security: is New Zealand a land of plenty? New Zealand Medical Journal, 114 (March), 141-145.

Pollitt, E. (1993). Iron deficiency and cognitive function. Annual Review of Nutrition, 13, 521-537.

Porpora, D. (2001). Do realists run regressions? In J. Lopez \& G. Potter (Eds.), After Postmodernism: an introduction to critical realism (pp. 260-268). London: The Athlone Press.

Poulton, R., Caspi, A., Milne, B., Thomson, W., Tayor, A., Sears, M., et al. (2002). Association between children's experience of socioeconomic disadvantage and adult health: a life-course study. The Lancet, 360 (9346), 1640.

Radimer, K., Olson, C., Greene, J., \& al, e. (1992). Understanding hunger and developing indicators to assess it in women and children. Journal of Nutrition Education, 24 (suppl), 36S-45S.

Raine, K., McIntyre, L., \& Dayle, J. B. (2003). The failure of charitable schooland community-based nutrition programmes to feed hungry children. Critical Public Health, 13 (2), 155-170. 
Reid, J. (1997). Developing food insecurity indicators for New Zealand: A thesis in fulfilment of Master of Public Health. Wellington: Wellington School of Medicine and Health Sciences, University of Otago.

Riches, G. (1997). Hunger, Welfare and Food Security: Emerging Strategies. In G. Riches (Ed.), First World Hunger. New York: St Martin's Press.

Riches, G. (2000). We are what we eat: Food security and social policy. Perception, 24 (1), Available from www.ccsd.ca/perception.

Riches, G. (2002). Food banks and food security: Welfare reform, human rights and social policy. Lessons from Canada. Social Policy and Administration, 36 (6), 648-663.

Robinson, M. (2002). The Right to Food: Achievements and Challenges. The World Food Summit: Five Years Later. Rome: United Nations Human Rights Commission.

Robson, C. (2002). Real World Research. Oxford: Blackwell Publishers.

Sadler, C., Rea, B., \& Nicholls, J. (1995). Combined Taranaki Foodbank Survey. New Plymouth: Taranaki Healthcare Ltd.

Saunders, A. (2004a). More and more hungry children. The Dominion Post, 30 November: A35.

Saunders, A. (2004b). Schools giving hungry kids free lunches. The Wellingtonian, 15 July, 2.

Saville-Smith, K. (1999). Familial Caregivers' Physical Abuse and Neglect of Children: A Literature Review. Wellington: Ministry of Social Policy and Department of Child, Youth and Family Services.

Sinfield, A. (2004). Ending Child Poverty in the UK: What can be learnt from the first five years? Presented to Child Poverty Action Group on 4 May 2004, St. Andrews on the Terrace, Wellington.

Smith, A. (1998). Understanding Children's Development: a New Zealand perspective (4th ed.). Wellington: Bridget Williams Books.

Smith, A. (2000). Children's Rights: an overview. In A. Smith, M. Gollop, K. Marshall \& K. Nairn (Eds.), Advocating for Children: International Perspectives of Children's Rights. Dunedin: University of Otago Press.

St. John, S. (2004). Understanding Income Changes as they Impact on Children. Paper presented at the Health Research Council's Health and Inequalities Symposium. 27 August. Te Papa, Wellington. 
Statistics New Zealand. (2004). Table 1: Average weekly expenditure by income group of household. In Household Economic Survey: Year ended 30 June 2004. Wellington: Statistics NZ. Available from www.stats.govt.nz.

Stephens, B., \& Waldegrave, C. (2004). Poverty and Policy: New Zealand Poverty Measurement Project. An address to Treasury 16 March 2004. Available from www.treasury.govt.nz/academiclinkages/stephens/tgls-stephens.pdf.

Storey, P., \& Chamberlin, R. (2001). Improving the take up of free school meals. London: Thomas Coram Research Unit, Institute of Education. Available from www.dfes.gov.uk/research.

Te Ora o Manukau - Manukau the Healthy City. (2003). The Collaborative Action Plan on Child Poverty in Manukau. Auckland: Manukau City Council.

Tolich, M. (2001). Self-administered Questionnaires. In M. Tolich (Ed.), Research Ethics in Aotearoa New Zealand. Auckland: Pearson Education.

UNICEF. (2000). A League Table of Child Poverty in Rich Nations. Florence: Innocenti Research Centre.

UNICEF. (2005). Nutrition: The Big Picture. In The State of the World's Children 2005. Available from http://www.unicef.org/nutrition/index_bigpicture.html.

United Nations. The United Nations Convention on the Rights of the Child. Wellington: Office of the Commissioner for Children.

Uttley, S. (1997). Hunger in New Zealand: A Question of Rights? In G. Riches (Ed.), First World Hunger: Food Security and Welfare Politics. London: Macmillan Press.

Waldegrave, C., King, P., \& Stuart, S. (1999). The monetry constraints and consumer behaviour in New Zealand low income households. Available from: www.geocities.com/ubinz/IR/pov99/199909waldegraveExecSum.html.

Waldegrave, C., Stephens, B., \& King, P. (2003). Assessing the progress on poverty reduction. Social Policy Journal of New Zealand, June, 197222. 
Waldegrave, C., \& Stuart, S. (1996). An analysis of the consumer behaviour of beneficiaries. Wellington: The Family Centre, for Wellington Anglican Diocesan Social Transformation Council.

World Health Organisation. (2004). Nutrition and Food Security: WHO Regional Office for Europe. Available from www.euro.who.int/nutrition/Security/SecTop.

Wylie, C., Thompson, J., \& Lythe, C. (2004). Competent Children at 12. Wellington: New Zealand Council for Educational Research. Available from www.nzcer.org.nz. 


\section{Appendices}

\section{Appendix 1: Information letter/email}

21 May 2004

The Principal

School name

School address

City/Area

Dear Principal

Re: Notification of upcoming research concerning children and food insecurity.

My name is Sarah Gerritsen and I am a post-graduate student at Victoria University of Wellington. I am writing a thesis entitled Children, Food and Poverty: Food insecurity among Wellington primary school students, for an MA (Applied) in Social Science Research. This thesis will explore the link between socio-economic status and food insecurity for primary school children, by correlating the incidence of food insecurity with school decile ratings. It will also record the variety of ways in which schools have responded to the issue. I am writing to notify you of this important forthcoming research.

In the first week of June, you will receive a questionnaire by mail that is being sent to every Wellington State and Integrated school with primary school aged children. It is important for the research that the situation in your school is represented in this sample. I would be grateful if you could please complete the questionnaire when you receive it and return it in the pre-paid envelope by 18 June 2004.

This project has the potential to influence policy decisions at a school, regional and national level. I hope that the results will also be of use to your school, by informing you of what is taking place in other schools throughout the region.

Thank you in advance for your time and effort in participating in this research.

Yours sincerely

Sarah Gerritsen

Sarah.Gerritsen@vuw.ac.nz 


\section{Appendix 2: Cover letter for questionnaire}

1 June 2004

Principal's name

School name

School address

City

Dear Principal

Re: Participation of your school in research concerning children and food insecurity.

My name is Sarah Gerritsen and I am a post-graduate student at Victoria University of Wellington. I am writing a thesis entitled Children, Food and Poverty: Food insecurity among Wellington primary school students for an MA (Applied) in Social Science Research. This thesis will explore connections between socio-economic status and food insecurity for children. It will also record the ways in which schools have responded to students who have not had breakfast and/or do not provision for lunch. I am writing to request your participation in this research project.

The enclosed questionnaire has been sent to every State and Integrated school in the Wellington region that has Year 1 to Year 6 students. It is very important for this research that your school is represented in the results. Your assistance, by completing the questionnaire and returning it in the prepaid envelope, would be greatly appreciated.

Responses will be treated in strict confidence, in accordance with Victoria University Human Ethics Committee guidelines. No names, addresses or identifying information of schools will be included in any of the reports or discussion about this research. The findings will be available online from February 2005 at www.hungrykids.info.

If you would like any further information about this research, please contact me directly, or my supervisor, Sandra Grey, using the email address or phone number below.

Thank you for giving your time to participate in this research.

Sincerely,

Sarah Gerritsen

Sarah.Gerritsen@vuw.ac.nz 


\section{Children, Food and Poverty: Food insecurity among Wellington primary school students}

\section{SCHOOL QUESTIONNAIRE}

Please return in the prepaid envelope by 25 June 2004

\section{Only include information about students in Year 1 to 6 at your school.}

Please tick the appropriate box or write in the space provided.

School name: [inserted from database]

1. How many children are on your current school roll, Year 1 to 6 ?

2. During May 2004, how many children in your school do you estimate were regularly hungry during the school day because they did not bring enough food from home or have enough money to buy food?

3. During May, how many children do you estimate regularly came to school without having eaten breakfast?

4. During May, how many children do you estimate regularly had no lunch, that is, they had no food from home and no money to buy food?

5. Does your school have any written policy regarding children and food?

$\square$ No

$\square$ Yes - please write the exact wording of this policy below or attach a copy of this policy to the questionnaire 
6. Does your school have any informal procedures teachers may follow when faced with children who have not eaten breakfast and/or have no lunch?

$\square$ No

$\square$ Yes - please give details of these informal procedures

7. Does your school provide free food for children who are hungry?

$\square$ No - we have no hungry children to feed

$\square$ No - but there are hungry children at our school

$\square$ Yes - sometimes

How many children are 'sometimes' provided with free food?

$\square$ Yes - daily

How many children are 'daily' provided with free food?

8. Who organises the provision of free food at your school?

$\square$ we do not provide free food

$\square$ the Principal

$\square$ a teacher

$\square$ a parent

$\square$ other - please give details 
9. How does your school fund the provision of free food?

[Please write n/a if your school does not provide free food]

10. How many children has your school referred to a Public Health Nurse in the past year, due to concern about their food security? *
None
$\square \quad 1-2$
$\square 3-5$
$\square$ 6-10
$\square$ Other - please specify number

11. How many children has your school referred to a Social Worker in the past year, due to concern about their food security? ${ }^{*}$
$\square$ None
$\square 1-2$
$\square 3-5$
$\square \quad 6-10$
$\square$ Other - please specify number

* Food security is defined as 'reliable access to the food needed for a healthy life... adequate in quality, quantity, safety and cultural appropriateness.' 
12. Please circle the number that best describes your reaction to the following statements:

\begin{tabular}{|l|c|c|c|c|c|}
\hline Statement & $\begin{array}{c}\text { 1 } \\
\text { Strongly } \\
\text { agree }\end{array}$ & $\begin{array}{c}\mathbf{2} \\
\text { Agree }\end{array}$ & $\begin{array}{c}\text { 3 } \\
\text { Don't } \\
\text { know }\end{array}$ & $\begin{array}{c}\mathbf{4} \\
\text { Disagree }\end{array}$ & $\begin{array}{c}5 \\
\text { Strongly } \\
\text { disagree }\end{array}$ \\
\hline $\begin{array}{l}\text { Some parents find it difficult to } \\
\text { provide breakfast for their } \\
\text { child(ren) every day. }\end{array}$ & 1 & 2 & 3 & 4 & 5 \\
\hline $\begin{array}{l}\text { Some parents find it difficult to } \\
\text { provide lunch for their } \\
\text { child(ren) every day. }\end{array}$ & 1 & 2 & 3 & 4 & 5 \\
\hline $\begin{array}{l}\text { Absenteeism is sometimes the } \\
\text { result of children having no } \\
\text { provision for lunch. }\end{array}$ & 1 & 2 & 3 & 4 & 5 \\
\hline $\begin{array}{l}\text { Parents are responsible for } \\
\text { ensuring that their child(ren) } \\
\text { has lunch every day. }\end{array}$ & 1 & 2 & 3 & 4 & 5 \\
\hline $\begin{array}{l}\text { Schools are responsible for } \\
\text { ensuring that every child has } \\
\text { lunch every day. }\end{array}$ & 1 & 2 & 3 & 4 & 5 \\
\hline $\begin{array}{l}\text { Schools are an important link in } \\
\text { the provision of social services } \\
\text { for children. }\end{array}$ & 1 & 2 & 3 & 4 & 5 \\
\hline
\end{tabular}

13. Please write any comments you would like to add on this issue.

Continue over the page if necessary.

\section{Thank you for taking the time to complete this questionnaire. Please return it in the envelope provided, before 25 June 2004.}

The findings of this thesis will be available from February 2005 online at www.hungrykids.info. 


\section{Appendix 4: Reminder card}

18 June 2004 YOUR SCHOOL'S PARTICIPATION
IN RESEARCH CONCERNING
CHILDREN AND FOOD INSECURITY

Dear Principal,

On 1 June, your school was sent a questionnaire for a research project entitled: Children, Food and Poverty: Food insecurity among Wellington primary school students.

I don't seem to have received a response from your school. It is not too late to post back the questionnaire and ensure your school is represented in the results. It would be greatly appreciated if you could please return the questionnaire ASAP. If you need another copy of the questionnaire, or you have any questions regarding this research, please contact me on the email address below.

Thank you for your time and effort participating in this research.

Sincerely, Sarah Gerritsen. MA (Applied) Social Science Research student. Victoria University of Wellington. Sarah.Gerritsen@vuw.ac.nz. www.hungrykids.info 


\section{Appendix 5: Results tables}

Table 1: Questionnaires returned by decile

\begin{tabular}{|l|c|c|c|}
\hline Decile range & $\begin{array}{c}\text { Questionnaires } \\
\text { sent }\end{array}$ & $\begin{array}{c}\text { Questionnaires } \\
\text { received }\end{array}$ & $\begin{array}{c}\text { Response rate } \\
\%\end{array}$ \\
\hline Decile 1 and 2 & 30 & 17 & 57 \\
\hline Decile 3 and 4 & 28 & 17 & 61 \\
\hline Decile 5 and 6 & 27 & 15 & 56 \\
\hline Decile 7 and 8 & 51 & 24 & 47 \\
\hline Decile 9 and 10 & 52 & 42 & 81 \\
\hline All deciles & $\mathbf{1 8 8}$ & $\mathbf{1 1 5}$ & $\mathbf{6 1}$ \\
\hline
\end{tabular}

Table 2: Questionnaires returned by regional area

\begin{tabular}{|l|c|c|c|}
\hline Regional area & $\begin{array}{c}\text { Questionnaires } \\
\text { sent }\end{array}$ & $\begin{array}{c}\text { Questionnaires } \\
\text { received }\end{array}$ & $\begin{array}{c}\text { Response rate } \\
\%\end{array}$ \\
\hline Carterton & 6 & 4 & 67 \\
\hline Kapiti Coast & 18 & 6 & 33 \\
\hline Lower Hutt & 42 & 24 & 57 \\
\hline Masterton & 13 & 8 & 62 \\
\hline Porirua & 27 & 16 & 59 \\
\hline South Wairarapa & 8 & 3 & 38 \\
\hline Upper Hutt & 14 & 10 & 71 \\
\hline Wellington & 60 & 44 & 73 \\
\hline All regional areas & $\mathbf{1 8 8}$ & $\mathbf{1 1 5}$ & $\mathbf{6 1}$ \\
\hline
\end{tabular}

Table 3: Children estimated to be 'regularly hungry' in May 2004 by decile

\begin{tabular}{|l|c|c|c|}
\hline Decile range & $\begin{array}{c}\text { Total number } \\
\text { of students }\end{array}$ & $\begin{array}{c}\text { 'Regularly } \\
\text { hungry' }\end{array}$ & $\begin{array}{c}\text { \% 'Regularly } \\
\text { hungry' }\end{array}$ \\
\hline Decile 1 and 2 & 3280 & 312 & 9.5 \\
\hline Decile 3 and 4 & 3229 & 197 & 6.1 \\
\hline Decile 5 and 6 & 2808 & 93 & 3.3 \\
\hline Decile 7 and 8 & 4290 & 137 & 3.2 \\
\hline Decile 9 and 10 & 9635 & 31 & 0.3 \\
\hline All deciles & $\mathbf{2 3 2 4 2}$ & $\mathbf{7 7 0}$ & $\mathbf{3 . 3}$ \\
\hline
\end{tabular}


Table 4: Children estimated to regularly have no breakfast in May 2004 by decile

\begin{tabular}{|l|c|c|c|}
\hline Decile range & $\begin{array}{c}\text { Total number } \\
\text { of students }\end{array}$ & 'No breakfast' & $\begin{array}{c}\text { \% 'No } \\
\text { breakfast' }\end{array}$ \\
\hline Decile 1 and 2 & 3280 & 458 & 14.0 \\
\hline Decile 3 and 4 & 3229 & 316 & 9.8 \\
\hline Decile 5 and 6 & 2808 & 172 & 6.1 \\
\hline Decile 7 and 8 & 4290 & 235 & 5.5 \\
\hline Decile 9 and 10 & 9635 & 288 & 3.0 \\
\hline All deciles & $\mathbf{2 3 2 4 2}$ & $\mathbf{1 4 6 9}$ & $\mathbf{6 . 3}$ \\
\hline
\end{tabular}

Table 5: Children estimated to regularly have no lunch in May 2004 by decile

\begin{tabular}{|l|c|c|c|}
\hline Decile range & $\begin{array}{c}\text { Total number } \\
\text { of students }\end{array}$ & 'No lunch' & \% 'No lunch' \\
\hline Decile 1 and 2 & 3280 & 202 & 6.2 \\
\hline Decile 3 and 4 & 3229 & 121 & 3.7 \\
\hline Decile 5 and 6 & 2808 & 46 & 1.6 \\
\hline Decile 7 and 8 & 4290 & 43 & 1.0 \\
\hline Decile 9 and 10 & 9635 & 25 & 0.3 \\
\hline All deciles & $\mathbf{2 3 2 4 2}$ & $\mathbf{4 3 7}$ & $\mathbf{1 . 9}$ \\
\hline
\end{tabular}

Table 6: Written policy in schools regarding children and food

\begin{tabular}{|l|c|c|}
\hline Written policy regarding children and food? & No. & \% \\
\hline Yes & 25 & 21.7 \\
\hline No & 88 & 76.5 \\
\hline No response & 2 & 1.7 \\
\hline Total & $\mathbf{1 1 5}$ & $\mathbf{1 0 0}$ \\
\hline
\end{tabular}

Table 7: Written policy in schools by decile

\begin{tabular}{|l|c|c|c|c|}
\hline Written policy & Yes & No & Total & $\begin{array}{c}\text { \% with } \\
\text { policy }\end{array}$ \\
\hline Decile 1 and 2 & 8 & 9 & 17 & $47.1 \%$ \\
\hline Decile 3 and 4 & 6 & 10 & 16 & $37.5 \%$ \\
\hline Decile 5 and 6 & 0 & 15 & 15 & $0.0 \%$ \\
\hline Decile 7 and 8 & 4 & 19 & 23 & $17.4 \%$ \\
\hline Decile 9 and 10 & 5 & 37 & 42 & $11.9 \%$ \\
\hline All deciles & $\mathbf{2 3}$ & $\mathbf{9 0}$ & $\mathbf{1 1 3}$ & $\mathbf{2 0 . 4 \%}$ \\
\hline
\end{tabular}


Table 8: Informal procedures in schools for teachers to follow when a child has not eaten breakfast or has no lunch

\begin{tabular}{|l|c|c|}
\hline $\begin{array}{l}\text { Informal procedures teachers follow when a child } \\
\text { has not eaten breakfast/has no lunch? }\end{array}$ & $\begin{array}{c}\text { No. of } \\
\text { schools }\end{array}$ & $\mathbf{\%}$ \\
\hline Yes & 104 & 90.4 \\
\hline No & 10 & 8.7 \\
\hline No response & 1 & 0.9 \\
\hline Total & $\mathbf{1 1 5}$ & $\mathbf{1 0 0}$ \\
\hline
\end{tabular}

Table 9: Informal procedures in schools by decile

\begin{tabular}{|l|c|c|c|c|}
\hline Informal procedure & Yes & No & Total & $\begin{array}{c}\text { \% with } \\
\text { procedure }\end{array}$ \\
\hline Decile 1 and 2 & 16 & 0 & 16 & $100.0 \%$ \\
\hline Decile 3 and 4 & 15 & 2 & 17 & $88.2 \%$ \\
\hline Decile 5 and 6 & 14 & 1 & 15 & $93.3 \%$ \\
\hline Decile 7 and 8 & 22 & 2 & 24 & $91.7 \%$ \\
\hline Decile 9 and 10 & 37 & 5 & 42 & $88.1 \%$ \\
\hline All deciles & $\mathbf{1 0 4}$ & $\mathbf{1 0}$ & $\mathbf{1 1 4}$ & $\mathbf{9 1 . 2 \%}$ \\
\hline
\end{tabular}

Table 10: Food provided to children who are hungry

\begin{tabular}{|l|l|}
\hline $\begin{array}{l}\text { Type of food provided for hungry children } \\
\text { (not asked in the questionnaire but many stated) }\end{array}$ & $\begin{array}{l}\text { No. of } \\
\text { schools }\end{array}$ \\
\hline Sandwiches or Toast & 45 \\
\hline Weetbix or Cereal & 9 \\
\hline Noodles & 4 \\
\hline Fruit & 5 \\
\hline Cheese & 5 \\
\hline Crackers & 4 \\
\hline Milo & 5 \\
\hline Pie / savouries & 2 \\
\hline Other: Biscuits / muesli bars / cornchips & 4 \\
\hline
\end{tabular}


Table 11: The provision of free food to hungry children

\begin{tabular}{|l|c|c|}
\hline $\begin{array}{l}\text { Does your school provide free food for children } \\
\text { who are hungry? }\end{array}$ & $\begin{array}{c}\text { No. of } \\
\text { schools }\end{array}$ & $\mathbf{\%}$ \\
\hline Yes - sometimes & 74 & 64.3 \\
\hline Yes - daily & 11 & 9.6 \\
\hline No - we have no hungry children & 30 & 26.1 \\
\hline No - but there are hungry children at our school & 1 & 0.9 \\
\hline No response & 0 & 0 \\
\hline Total & $\mathbf{1 1 5}$ & $\mathbf{1 0 0}$ \\
\hline
\end{tabular}

Table 12: The provision of free food to hungry children by decile

\begin{tabular}{|l|c|c|c|c|}
\hline $\begin{array}{l}\text { Schools that provide } \\
\text { free food }\end{array}$ & Sometimes & Daily & $\begin{array}{c}\text { Total no. } \\
\text { of } \\
\text { schools }\end{array}$ & $\begin{array}{c}\text { \% that } \\
\text { provide } \\
\text { free food }\end{array}$ \\
\hline Decile 1 and 2 & 11 & 6 & 17 & 100 \\
\hline Decile 3 and 4 & 12 & 4 & 17 & 94.1 \\
\hline Decile 5 and 6 & 14 & 0 & 15 & 93.3 \\
\hline Decile 7 and 8 & 20 & 1 & 24 & 87.5 \\
\hline Decile 9 and 10 & 17 & 0 & 42 & 40.5 \\
\hline All deciles & $\mathbf{7 4}$ & $\mathbf{1 1}$ & $\mathbf{1 1 5}$ & $\mathbf{7 3 . 9}$ \\
\hline
\end{tabular}

Table 13: Schools that do not provide free food to hungry children by decile

\begin{tabular}{|l|c|c|c|c|}
\hline $\begin{array}{l}\text { Schools that do not } \\
\text { provide free food }\end{array}$ & $\begin{array}{l}\text { Have no } \\
\text { hungry } \\
\text { children }\end{array}$ & $\begin{array}{l}\text { There are } \\
\text { hungry } \\
\text { children }\end{array}$ & $\begin{array}{l}\text { Total no. } \\
\text { of } \\
\text { schools }\end{array}$ & $\begin{array}{l}\text { \% do not } \\
\text { provide } \\
\text { free food }\end{array}$ \\
\hline Decile 1 and 2 & 0 & 0 & 17 & 0 \\
\hline Decile 3 and 4 & 1 & 0 & 17 & 5.9 \\
\hline Decile 5 and 6 & 1 & 1 & 15 & 13.3 \\
\hline Decile 7 and 8 & 3 & 0 & 24 & 12.5 \\
\hline Decile 9 and 10 & 25 & 0 & 42 & 59.5 \\
\hline All deciles & $\mathbf{3 0}$ & $\mathbf{1}$ & $\mathbf{1 1 5}$ & $\mathbf{2 7 . 0}$ \\
\hline
\end{tabular}


Table 14: Numbers of children receiving free food by decile

\begin{tabular}{|l|c|c|c|c|}
\hline $\begin{array}{l}\text { How many children } \\
\text { receive free food? }\end{array}$ & Sometimes & Daily & $\begin{array}{c}\text { Total no. } \\
\text { of } \\
\text { students }\end{array}$ & $\begin{array}{c}\text { \% that are } \\
\text { given free } \\
\text { food }\end{array}$ \\
\hline Decile 1 and 2 & 162 & 16 & 3280 & 5.4 \\
\hline Decile 3 and 4 & 59 & 19 & 3229 & 2.4 \\
\hline Decile 5 and 6 & 29 & 0 & 2808 & 1.0 \\
\hline Decile 7 and 8 & 39 & 5 & 4290 & 1.0 \\
\hline Decile 9 and 10 & 22 & 0 & 9635 & 0.2 \\
\hline All deciles & $\mathbf{3 1 1}$ & $\mathbf{4 0}$ & $\mathbf{2 3 2 4 2}$ & $\mathbf{1 . 5}$ \\
\hline
\end{tabular}

Table 15: Organisation of free food in schools

\begin{tabular}{|l|c|c|c|}
\hline $\begin{array}{l}\text { Who organises the provision of } \\
\text { free food at your school? }\end{array}$ & $\begin{array}{c}\text { No. of } \\
\text { schools }\end{array}$ & $\begin{array}{c}\text { \% of all } \\
\mathbf{1 1 5} \\
\text { schools }\end{array}$ & $\begin{array}{c}\text { \% of } \mathbf{8 5} \\
\text { 'free food' } \\
\text { schools }\end{array}$ \\
\hline We do not provide free food & 27 & 23.5 & - \\
\hline Teacher/s or teacher aide/s & 52 & 45.2 & 61.2 \\
\hline The Principal & 36 & 31.3 & 42.4 \\
\hline Office staff & 34 & 29.6 & 40.0 \\
\hline Parent/s or Board of Trustees & 4 & 3.5 & 4.7 \\
\hline Other (Community group) & 1 & 0.9 & 1.2 \\
\hline No response & 1 & 0.9 & - \\
\hline Total & $\mathbf{1 5 5}^{\mathbf{1 7}}$ & - & - \\
\hline
\end{tabular}

${ }^{17}$ Total equals more than 115 schools as some principals gave multiple answers to this question 
Table 16: Funding of free food in schools

\begin{tabular}{|l|c|c|c|}
\hline $\begin{array}{l}\text { How does your school fund the } \\
\text { provision of free food? }\end{array}$ & $\begin{array}{c}\text { No. of } \\
\text { schools }\end{array}$ & $\begin{array}{c}\text { \% of all } \\
\mathbf{1 1 5} \\
\text { schools }\end{array}$ & $\begin{array}{c}\text { \% of 85 } \\
\text { 'free food' } \\
\text { schools }\end{array}$ \\
\hline We do not provide free food & 27 & 23.5 & - \\
\hline School & & & \\
\hline Operations grant & 45 & 39.1 & 52.9 \\
\hline Board of Trustees funds & 2 & 1.7 & 2.4 \\
\hline Tuck shop profits & 6 & 5.2 & 7.1 \\
\hline Fundraising leftovers & 6 & 5.2 & 7.1 \\
\hline Discretionary hardship fund & 2 & 1.7 & 2.4 \\
\hline Pastoral care budget & 2 & 1.7 & 2.4 \\
\hline Community & 11 & & \\
\hline $\begin{array}{c}\text { Church/community group or } \\
\text { donations }\end{array}$ & 1 & 9.6 & 12.9 \\
\hline$\quad$ Borrow from attached preschool & 1 & 0.9 & 1.8 \\
\hline Individuals & 12 & 10.4 & 14.1 \\
\hline$\quad$ Teachers/Principal & 1 & 0.9 & - \\
\hline No response & $\mathbf{1 1 5}$ & $\mathbf{1 0 0}$ & $\mathbf{1 0 0}$ \\
\hline Total & & & \\
\hline
\end{tabular}

Table 17: Numbers of children referred to a Public Health Nurse in the past year due to a concern for their food security

\begin{tabular}{|l|c|c|}
\hline $\begin{array}{l}\text { How many children has your school referred to a } \\
\text { PHN in the past year, due to food insecurity } \\
\text { concerns? }\end{array}$ & $\begin{array}{c}\text { No. of } \\
\text { schools }\end{array}$ & $\%$ \\
\hline None & 87 & 75.7 \\
\hline $1-2$ & 12 & 10.4 \\
\hline $3-5$ & 13 & 11.3 \\
\hline $6-10$ & 1 & 0.9 \\
\hline $10+$ & 0 & 0 \\
\hline No response & 2 & 1.7 \\
\hline Total & $\mathbf{1 1 5}$ & $\mathbf{1 0 0}$ \\
\hline
\end{tabular}


Table 18: Referrals to a Public Health Nurse by decile

\begin{tabular}{|l|c|c|c|c|c|c|}
\hline $\begin{array}{l}\text { Schools that } \\
\text { referred to a PHN }\end{array}$ & $\mathbf{1 - 2}$ & $\mathbf{3 - 5}$ & $\mathbf{6 - 1 0}$ & $\mathbf{1 0 +}$ & $\begin{array}{c}\text { Total no. } \\
\text { of } \\
\text { schools }\end{array}$ & $\begin{array}{c}\text { \% that } \\
\text { referred } \\
\text { to PHN }\end{array}$ \\
\hline Decile 1 and 2 & 2 & 4 & 1 & 0 & 16 & 43.8 \\
\hline Decile 3 and 4 & 2 & 4 & 0 & 0 & 17 & 35.3 \\
\hline Decile 5 and 6 & 3 & 2 & 0 & 0 & 14 & 35.7 \\
\hline Decile 7 and 8 & 2 & 3 & 0 & 0 & 24 & 20.8 \\
\hline Decile 9 and 10 & 3 & 0 & 0 & 0 & 42 & 7.1 \\
\hline All deciles & $\mathbf{1 2}$ & $\mathbf{1 3}$ & $\mathbf{1}$ & $\mathbf{0}$ & $\mathbf{1 1 3}$ & $\mathbf{2 2 . 6}$ \\
\hline
\end{tabular}

Table 19: Numbers of children referred to Social Worker in the past year due to a concern for their food security

\begin{tabular}{|l|c|c|}
\hline $\begin{array}{l}\text { How many children has your school referred to a } \\
\text { Social Worker in the past year, due to food } \\
\text { insecurity concerns? }\end{array}$ & $\begin{array}{c}\text { No. of } \\
\text { schools }\end{array}$ & $\%$ \\
\hline None & 95 & 82.6 \\
\hline $1-2$ & 11 & 9.6 \\
\hline $3-5$ & 5 & 4.3 \\
\hline $6-10$ & 1 & 0.9 \\
\hline $10+$ & 1 & 0.9 \\
\hline No response & 2 & 1.7 \\
\hline Total & $\mathbf{1 1 5}$ & $\mathbf{1 0 0}$ \\
\hline
\end{tabular}

Table 20: Referrals to a Social Worker by decile

\begin{tabular}{|l|c|c|c|c|c|c|}
\hline $\begin{array}{l}\text { Schools that } \\
\text { referred to a SW }\end{array}$ & $\mathbf{1 - 2}$ & $\mathbf{3 - 5}$ & $\mathbf{6 - 1 0}$ & $\mathbf{1 0 +}$ & $\begin{array}{c}\text { Total no. } \\
\text { of } \\
\text { schools }\end{array}$ & $\begin{array}{c}\text { \% that } \\
\text { referred } \\
\text { to SW }\end{array}$ \\
\hline Decile 1 and 2 & 5 & 3 & 0 & 1 & 16 & 56.3 \\
\hline Decile 3 and 4 & 1 & 2 & 1 & 0 & 17 & 23.5 \\
\hline Decile 5 and 6 & 0 & 0 & 0 & 0 & 15 & 0 \\
\hline Decile 7 and 8 & 2 & 0 & 0 & 0 & 23 & 8.7 \\
\hline Decile 9 and 10 & 3 & 0 & 0 & 0 & 42 & 7.1 \\
\hline All deciles & $\mathbf{1 1}$ & $\mathbf{5}$ & $\mathbf{1}$ & $\mathbf{1}$ & $\mathbf{1 1 5}$ & $\mathbf{1 5 . 7}$ \\
\hline
\end{tabular}


Table 21: Correlation between numbers of hungry children in May 2004 with referrals made to a welfare professional in past twelve months

\begin{tabular}{|l|l|l|}
\hline & $\begin{array}{c}\text { No. of } \\
\text { schools }\end{array}$ & \multicolumn{1}{|c|}{$\%$} \\
\hline $\begin{array}{l}\text { No hungry children in May and no referrals to SW/PHN } \\
\text { in past } 12 \text { months }\end{array}$ & 47 & 40.9 \\
\hline $\begin{array}{l}\text { No hungry children in May and has referred children to } \\
\text { SW/PHN in past 12 months }\end{array}$ & 2 & 1.7 \\
\hline $\begin{array}{l}\text { Some hungry children in May and no referrals to } \\
\text { SW/PHN in past 12 months }\end{array}$ & 35 & 30.4 \\
\hline $\begin{array}{l}\text { Some hungry children in May and has referred children } \\
\text { to SW/PHN in past 12 months }\end{array}$ & 28 & 24.3 \\
\hline No response to at least one of the questions & 3 & 2.6 \\
\hline Total & 115 & 100 \\
\hline
\end{tabular}

Table 22: Principals' opinions on the difficulty for parents to provide breakfast for their child(ren) every day

\begin{tabular}{|l|c|c|}
\hline $\begin{array}{l}\text { Some parents find it difficult to provide breakfast } \\
\text { for their child(ren) everyday }\end{array}$ & $\begin{array}{c}\text { No. of } \\
\text { Principals }\end{array}$ & $\mathbf{\%}$ \\
\hline Strongly agree (1) & 10 & 8.7 \\
\hline Agree (2) & 51 & 44.3 \\
\hline Don't know (3) & 16 & 13.9 \\
\hline Disagree (4) & 19 & 16.5 \\
\hline Strongly disagree (5) & 16 & 13.9 \\
\hline No response & 3 & 2.6 \\
\hline Total & $\mathbf{1 1 5}$ & $\mathbf{1 0 0}$ \\
\hline
\end{tabular}

Table 23: Principals' opinions on the difficulty for parents to provide breakfast for their child(ren) every day by decile

\begin{tabular}{|l|c|c|c|c|c|c|c|}
\hline & $\mathbf{1}$ & $\mathbf{2}$ & $\mathbf{3}$ & $\mathbf{4}$ & $\mathbf{5}$ & $\begin{array}{c}\text { Total no. } \\
\text { of } \\
\text { principals }\end{array}$ & $\begin{array}{c}\text { \% that } \\
\text { agree } \\
\mathbf{( 1 \text { and 2) }}\end{array}$ \\
\hline Decile 1 and 2 & 5 & 9 & 2 & 1 & 0 & 17 & 82.4 \\
\hline Decile 3 and 4 & 3 & 7 & 3 & 3 & 1 & 17 & 58.8 \\
\hline Decile 5 and 6 & 0 & 9 & 2 & 3 & 1 & 15 & 60.0 \\
\hline Decile 7 and 8 & 1 & 8 & 4 & 6 & 2 & 21 & 42.8 \\
\hline Decile 9 and 10 & 1 & 18 & 5 & 6 & 12 & 42 & 45.2 \\
\hline All deciles & $\mathbf{1 0}$ & $\mathbf{5 1}$ & $\mathbf{1 6}$ & $\mathbf{1 9}$ & $\mathbf{1 6}$ & $\mathbf{1 1 2}$ & $\mathbf{5 4 . 5}$ \\
\hline
\end{tabular}


Table 24: Principals' opinions on the difficulty for parents to provide lunch for their child(ren) every day

\begin{tabular}{|l|c|c|}
\hline $\begin{array}{l}\text { Some parents find it difficult to provide lunch for } \\
\text { their child(ren) everyday }\end{array}$ & $\begin{array}{c}\text { No. of } \\
\text { Principals }\end{array}$ & $\%$ \\
\hline Strongly agree (1) & 11 & 9.6 \\
\hline Agree (2) & 53 & 46.1 \\
\hline Don't know (3) & 9 & 7.8 \\
\hline Disagree (4) & 23 & 20.0 \\
\hline Strongly disagree (5) & 16 & 13.9 \\
\hline No response & 3 & 2.6 \\
\hline Total & $\mathbf{1 1 5}$ & $\mathbf{1 0 0}$ \\
\hline
\end{tabular}

Table 25: Principals' opinions on the difficulty for parents to provide lunch for their child(ren) every day by decile

\begin{tabular}{|l|c|c|c|c|c|c|c|}
\hline & $\mathbf{1}$ & $\mathbf{2}$ & $\mathbf{3}$ & $\mathbf{4}$ & $\mathbf{5}$ & $\begin{array}{c}\text { Total no. } \\
\text { of } \\
\text { principals }\end{array}$ & $\begin{array}{c}\text { \% that } \\
\text { agree } \\
\mathbf{( 1 \text { and 2) }}\end{array}$ \\
\hline Decile 1 and 2 & 6 & 9 & 0 & 2 & 0 & 17 & 88.2 \\
\hline Decile 3 and 4 & 3 & 8 & 2 & 4 & 0 & 17 & 64.7 \\
\hline Decile 5 and 6 & 0 & 9 & 1 & 4 & 1 & 15 & 60.0 \\
\hline Decile 7 and 8 & 1 & 9 & 3 & 5 & 3 & 21 & 47.6 \\
\hline Decile 9 and 10 & 1 & 18 & 3 & 8 & 12 & 42 & 45.2 \\
\hline All deciles & $\mathbf{1 1}$ & $\mathbf{5 3}$ & $\mathbf{9}$ & $\mathbf{2 3}$ & $\mathbf{1 6}$ & $\mathbf{1 1 2}$ & $\mathbf{5 7 . 1}$ \\
\hline
\end{tabular}

Table 26: Principals' opinions on whether parents are responsible for ensuring that their child(ren) has lunch every day

\begin{tabular}{|l|c|c|}
\hline $\begin{array}{l}\text { Parents are responsible for ensuring that their } \\
\text { child(ren) has lunch every day }\end{array}$ & $\begin{array}{c}\text { No. of } \\
\text { Principals }\end{array}$ & $\mathbf{\%}$ \\
\hline Strongly agree (1) & 82 & 71.3 \\
\hline Agree (2) & 31 & 27.0 \\
\hline Don't know (3) & 0 & 0 \\
\hline Disagree (4) & 1 & 0.9 \\
\hline Strongly disagree (5) & 0 & 0 \\
\hline No response & 1 & 0.9 \\
\hline Total & $\mathbf{1 1 5}$ & $\mathbf{1 0 0}$ \\
\hline
\end{tabular}


Table 27: Principals' opinions on whether parents are responsible for ensuring that their child(ren) has lunch every day by decile

\begin{tabular}{|l|c|c|c|c|c|c|c|}
\hline & $\mathbf{1}$ & $\mathbf{2}$ & $\mathbf{3}$ & $\mathbf{4}$ & $\mathbf{5}$ & $\begin{array}{c}\text { Total no. } \\
\text { of } \\
\text { principals }\end{array}$ & $\begin{array}{c}\text { \% that } \\
\text { agree } \\
\mathbf{( 1 \text { and 2) }}\end{array}$ \\
\hline Decile 1 and 2 & 11 & 6 & 0 & 0 & 0 & 17 & 100 \\
\hline Decile 3 and 4 & 13 & 4 & 0 & 0 & 0 & 17 & 100 \\
\hline Decile 5 and 6 & 12 & 3 & 0 & 0 & 0 & 15 & 100 \\
\hline Decile 7 and 8 & 14 & 9 & 0 & 0 & 0 & 23 & 100 \\
\hline Decile 9 and 10 & 32 & 10 & 0 & 0 & 0 & 42 & 100 \\
\hline All deciles & $\mathbf{8 2}$ & $\mathbf{3 2}$ & $\mathbf{0}$ & $\mathbf{0}$ & $\mathbf{0}$ & $\mathbf{1 1 4}$ & $\mathbf{1 0 0}$ \\
\hline
\end{tabular}

NB: A Decile 1 principal 'disagreed' with the above statement but then wrote "but they should be" so their answer has been counted as 'agree' above.

Table 28: Principals' opinions on whether schools are responsible for ensuring that every child has lunch every day

\begin{tabular}{|l|c|c|}
\hline $\begin{array}{l}\text { Schools are responsible for ensuring that every } \\
\text { child has lunch every day }\end{array}$ & $\begin{array}{c}\text { No. of } \\
\text { Principals }\end{array}$ & $\mathbf{\%}$ \\
\hline Strongly agree (1) & 12 & 10.4 \\
\hline Agree (2) & 30 & 26.1 \\
\hline Don't know (3) & 4 & 3.5 \\
\hline Disagree (4) & 41 & 35.7 \\
\hline Strongly disagree (5) & 25 & 21.7 \\
\hline No response & 3 & 2.6 \\
\hline Total & $\mathbf{1 1 5}$ & $\mathbf{1 0 0}$ \\
\hline
\end{tabular}

Table 29 Principals' opinions on whether schools are responsible for ensuring that every child has lunch every day by decile

\begin{tabular}{|l|c|c|c|c|c|c|c|}
\hline & $\mathbf{1}$ & $\mathbf{2}$ & $\mathbf{3}$ & $\mathbf{4}$ & $\mathbf{5}$ & $\begin{array}{c}\text { Total no. } \\
\text { of } \\
\text { principals }\end{array}$ & $\begin{array}{c}\text { \% that } \\
\text { agree } \\
\mathbf{( 1} \text { and 2) }\end{array}$ \\
\hline Decile 1 and 2 & 4 & 1 & 1 & 9 & 1 & 16 & 31.3 \\
\hline Decile 3 and 4 & 1 & 7 & 0 & 4 & 5 & 17 & 47.1 \\
\hline Decile 5 and 6 & 1 & 3 & 0 & 6 & 5 & 15 & 26.7 \\
\hline Decile 7 and 8 & 3 & 8 & 0 & 10 & 2 & 23 & 47.8 \\
\hline Decile 9 and 10 & 3 & 11 & 3 & 12 & 12 & 41 & 34.1 \\
\hline All deciles & $\mathbf{1 2}$ & $\mathbf{3 0}$ & $\mathbf{4}$ & $\mathbf{4 1}$ & $\mathbf{2 5}$ & $\mathbf{1 1 2}$ & $\mathbf{3 7 . 5}$ \\
\hline
\end{tabular}


Table 30: Principals' opinions on whether absenteeism is sometimes the result of children having no provision for lunch

\begin{tabular}{|l|c|c|}
\hline $\begin{array}{l}\text { Absenteeism is sometimes the result of children } \\
\text { having no provision for lunch }\end{array}$ & $\begin{array}{c}\text { No. of } \\
\text { Principals }\end{array}$ & $\%$ \\
\hline Strongly agree (1) & 13 & 11.3 \\
\hline Agree (2) & 31 & 27.0 \\
\hline Don't know (3) & 20 & 17.4 \\
\hline Disagree (4) & 24 & 20.9 \\
\hline Strongly disagree (5) & 25 & 21.7 \\
\hline No response & 2 & 1.7 \\
\hline Total & $\mathbf{1 1 5}$ & $\mathbf{1 0 0}$ \\
\hline
\end{tabular}

Table 31: Principals' opinions on whether absenteeism is sometimes the result of children having no provision for lunch by decile

\begin{tabular}{|l|c|c|c|c|c|c|c|}
\hline & $\mathbf{1}$ & $\mathbf{2}$ & $\mathbf{3}$ & $\mathbf{4}$ & $\mathbf{5}$ & $\begin{array}{c}\text { Total no. } \\
\text { of } \\
\text { principals }\end{array}$ & $\begin{array}{c}\text { \% that } \\
\text { agree } \\
\mathbf{( 1 \text { and 2) }}\end{array}$ \\
\hline Decile 1 and 2 & 7 & 8 & 1 & 1 & 0 & 17 & 88.2 \\
\hline Decile 3 and 4 & 4 & 7 & 1 & 1 & 4 & 17 & 64.7 \\
\hline Decile 5 and 6 & 0 & 5 & 2 & 5 & 3 & 15 & 33.3 \\
\hline Decile 7 and 8 & 2 & 5 & 4 & 8 & 3 & 22 & 31.8 \\
\hline Decile 9 and 10 & 0 & 6 & 12 & 9 & 15 & 42 & 14.3 \\
\hline All deciles & $\mathbf{1 3}$ & $\mathbf{3 1}$ & $\mathbf{2 0}$ & $\mathbf{2 4}$ & $\mathbf{2 5}$ & $\mathbf{1 1 3}$ & $\mathbf{3 8 . 9}$ \\
\hline
\end{tabular}

Table 32: Principals' opinions on whether schools are an important link in the provision of social services for children

\begin{tabular}{|l|c|c|}
\hline $\begin{array}{l}\text { Schools are an important link in the provision of } \\
\text { social services for children }\end{array}$ & $\begin{array}{c}\text { No. of } \\
\text { Principals }\end{array}$ & $\mathbf{\%}$ \\
\hline Strongly agree (1) & 52 & 45.2 \\
\hline Agree (2) & 57 & 49.6 \\
\hline Don't know (3) & 1 & 0.9 \\
\hline Disagree (4) & 1 & 0.9 \\
\hline Strongly disagree (5) & 3 & 2.6 \\
\hline No response & 1 & 0.9 \\
\hline Total & $\mathbf{1 1 5}$ & $\mathbf{1 0 0}$ \\
\hline
\end{tabular}


Table 33: Principals' opinions on whether schools are an important link in the provision of social services for children by decile

\begin{tabular}{|l|c|c|c|c|c|c|c|}
\hline & $\mathbf{1}$ & $\mathbf{2}$ & $\mathbf{3}$ & $\mathbf{4}$ & $\mathbf{5}$ & $\begin{array}{c}\text { Total no. } \\
\text { of } \\
\text { principals }\end{array}$ & $\begin{array}{c}\text { \% that } \\
\text { agree } \\
\mathbf{( 1} \text { and 2) }\end{array}$ \\
\hline Decile 1 and 2 & 14 & 3 & 0 & 0 & 0 & 17 & 100 \\
\hline Decile 3 and 4 & 4 & 13 & 0 & 0 & 0 & 17 & 100 \\
\hline Decile 5 and 6 & 7 & 7 & 1 & 0 & 0 & 15 & 93.3 \\
\hline Decile 7 and 8 & 10 & 13 & 0 & 0 & 0 & 23 & 100 \\
\hline Decile 9 and 10 & 17 & 21 & 0 & 1 & 3 & 42 & 90.5 \\
\hline All deciles & $\mathbf{5 2}$ & $\mathbf{5 7}$ & $\mathbf{1}$ & $\mathbf{1}$ & $\mathbf{3}$ & $\mathbf{1 1 4}$ & $\mathbf{9 5 . 6}$ \\
\hline
\end{tabular}




\title{
Appendix 6: Extra information provided by participating schools
}

\author{
a. Healthy Food / Nutrition policies ${ }^{18}$
}

1. Policy from a Decile 1 school

\section{Rationale}

School lunches must set an example of good nutrition so that students may learn to make responsible personal choices for present and future healthy eating needs.

\section{Purpose}

- To encourage students to eat a wide variety of healthy foods.

- To provide a learning situation for improving awareness of good nutrition as a health factor.

- To incorporate the healthy lunch into the school's Health Programme as part of our commitment to improving the immediate and long term health of all our students.

\section{Broad guidelines}

- Promote the use of brads, fruits and vegetables as a top priority.

- Discourage the consumption of foods with high fat, refined sugar, salt and food colouring content.

- Ensure hygienic preparation, packing and storage of foods in a Smokefree environment.

- A variety of healthy foods are included in the choices provided for children ordering lunch.

- Support this project with learning programmes in the Health/Social Studies and other curriculum areas.

\section{Implementation}

- Parent/Teachers/Children will make appropriate choices for healthy eating.

- Children will be able to order lunch each morning.

- Children who arrive with no lunch will be given sandwiches.

- Children who bring inappropriate food from home will be encouraged to have it replaced by healthy food.

- Teachers will monitor eating habits at lunch time when they are with the children for the first ten minutes of the lunchtime session.

${ }^{18}$ Fifteen principals attached their school's policy regarding food to the returned questionnaire. The policies recorded here are some of the most comprehensive. 


\section{Policy from a Decile 4 school}

\section{Rationale}

We wish to educate our children and their families as to the importance of eating healthy food and drinking plenty of water. This helps to improve concentration and the ability to learn, general health and wellbeing, and sets them on the path to a healthy lifestyle.

\section{Purposes}

1. Establish guidelines for school lunches

2. Incorporate healthy food studies into the Health Curriculum delivery annually

3. Develop an awareness in children of desirable eating habits

4. Ensure fundraising with food is in keeping with the Healthy Food policy

5. Identify and monitor foods which are unacceptable for children to eat at school

\section{Guidelines}

1. At the beginning of each term a guideline sheet on appropriate and unacceptable food will be sent home.

2. The school lunch order scheme will identify food that can be ordered everyday and food that can only be ordered one day a week.

3. The principal will provide a copy of this policy to parents and caregivers of new enrolments.

4. In addition to Health Curriculum studies, staff will regularly discuss healthy food and eating habits with children. They will also monitor what children eat on a daily basis, as time permits.

5. The school newsletter will be used regularly to give healthy food information.

6. Treat foods may be used as part of special occasions. e.g. school discos and galas.

7. Staff will monitor what children are bringing to school and contact parents where there is a concern.

8. Should a child have insufficient food, the school will provide a basic lunch. Parents will be contacted about this.

9. When children bring items from the unacceptable list, they will be confiscated until the end of the day and, if necessary, replaced with an alternative food. 
3. Policy from a Decile 10 school

\section{Rationale}

Good nutrition is essential for maintaining good health. Students and staff should have access to a variety of foods that reflect the National Nutrition Guidelines and the food pyramid.

We recognise the importance of actively encouraging children to be award of foods which promote health and for children to take responsibility for choices they make about eating.

\section{Purpose}

- To provide a suitable nutritious food service for children who wish to buy lunches

- To encourage the children to eat their lunch

- To support and reinforce the schools health programme on nutrition

- Encourage parents and children to be aware of the importance of eating healthy food

- To improve the health of pupils

\section{Guidelines}

1. Healthy and nutritious school lunches will include foods low in fats, sugar and salt, where possible.

2. Provide a variety of lunch foods will be provided so students may learn to make responsible choices for themselves.

3. Consumption of water will be encouraged as an alternative to cordials and soft drinks.

4. When teachers are concerned about a child's diet/eating, they will contact a parent/guardian.

5. The Health programme will encourage children to be aware of their food needs.

6. $\quad$ Ensure parents enrolling children receive a "Healthy at 5" (school booklet which talks about healthy eating) or other healthy eating literature.

7. Eating of chewing gum is prohibited at school. On special occasions lollies can be shared equally among the child's class or the whole school.

\section{Conclusion}

By fostering healthy eating habits within the school, we are encouraging life long healthy eating patterns. 
4. Policy from a Kura Kaupapa Māori school

Te Aho Matua: 1.7:

He tapu te tinana o te tangata. Nō reira he mahi nui tērā, ko te whakaako i te tamaiti ki nga ahuatanga, whakapakari i tōna tinana, kia tipu ai tōna hauora. Kia mohio te hunga tamariki ki ngā kai pai, ki ngā kai kino. Kiā mohio hoki ki te painga o te korikori tinana, o te mirimiri tinana, o ngā rongoa a Tane Whakapiripiri. Kia kaua ia e tukino i tōna tinana, i te tinana o tētehi atu.

Rationale: Te Kura Kaupapa Māori will implement this policy in the belief that a healthy diet and regular exercise are essential parts of our children's education. 


\section{b. Template of a letter that a Decile 9 school sends to parents regarding food insecurity issues}

Date:

Dear

\section{Re: UNHEALTHY EATING}

This is to inform you that the school has concern regarding your child's eating habits.

Teachers have observed that has not been receiving adequate nourishment at lunchtime, specifically:

- Having little or no lunch at all

○ Eating 'junk' food only

Healthy diet is essential to normal physical, intellectual, social and emotional growth. Poor diet can have a negative effect on all aspects of learning in the classroom.

Please discuss this matter with and point out the necessity of good healthy eating habits.

If you wish to discuss this further please contact the school.

Yours faithfully, 


\section{c. Flow chart used in a Decile 1 school to assist teachers when a student has no lunch.}

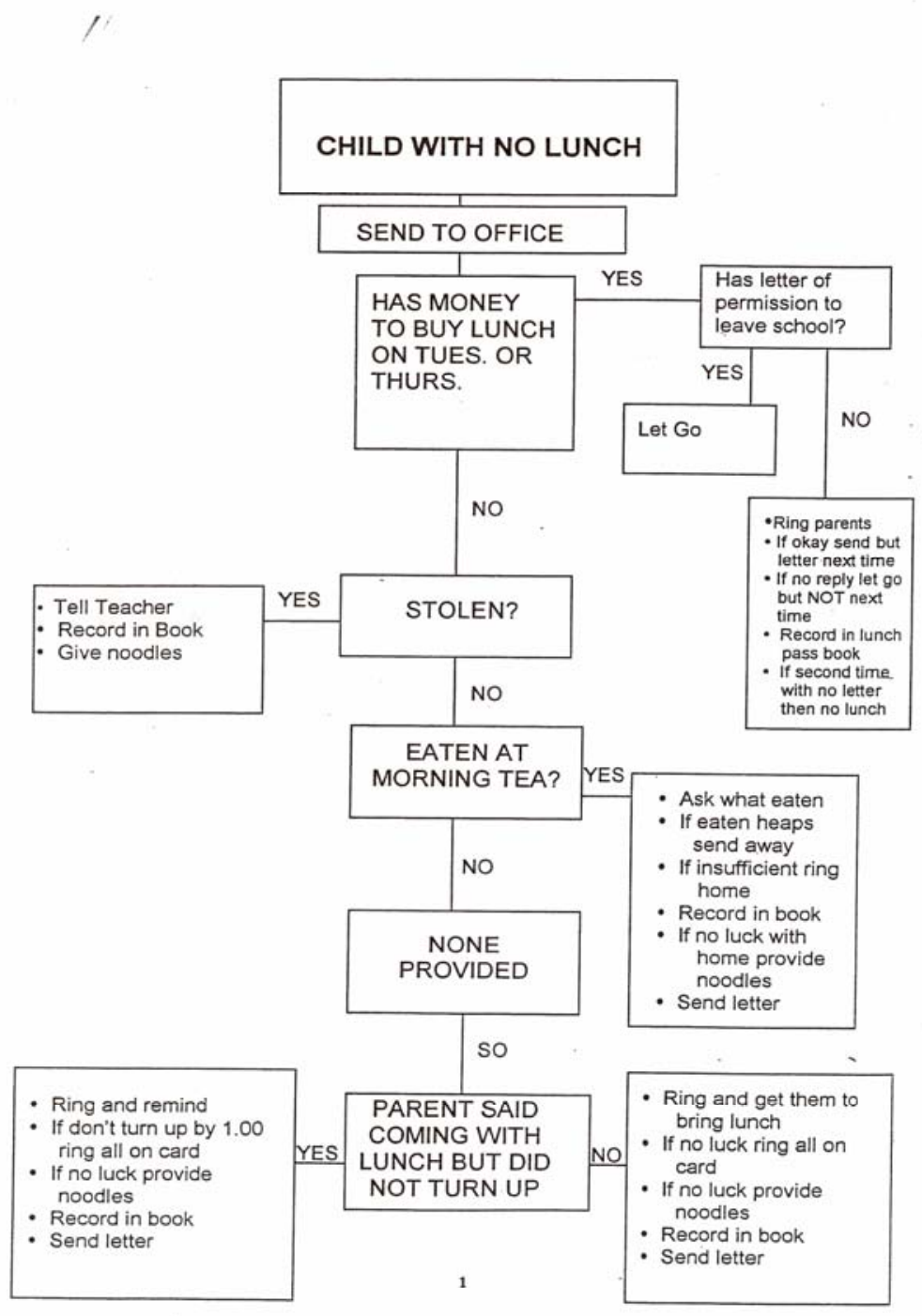

